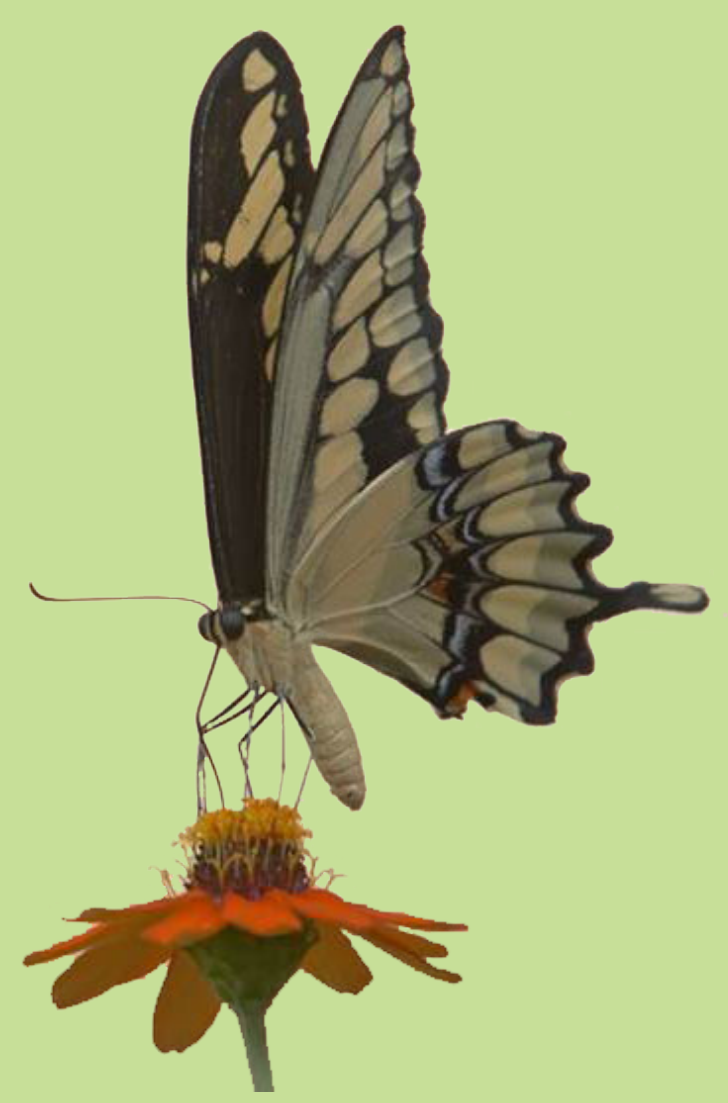

\title{
Economic Implications of Growing Populations and Changing Demographic Structures
}

Christopher NORTH

KIOES Opinions 3 (2014)

KIOES Opinions are published by the Commission for Interdisciplinary Ecological Studies (KIOES) of the Austrian Academy of Sciences (ÖAW). KIOES publishes current opinions of its members and staff related to topical subjects on an irregular basis in KIOES Opinions. The target audience includes scientists, policy makers and the public. Opinions expressed in this article are solely those of the author, and they do not necessarily reflect in any way those of KIOES or ÖAW. \section{$\bigcup_{\substack{\text { Austrinn Academy } \\ \text { of sciences }}} \mathrm{AW}$}

More information about KIOES and download of KIOES Opinions at http://www.oeaw.ac.at/kioes 


\section{Table of Contents}

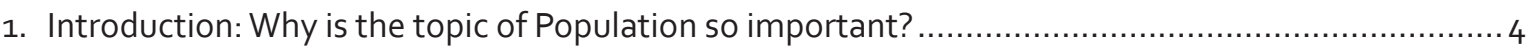

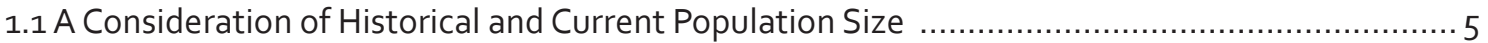

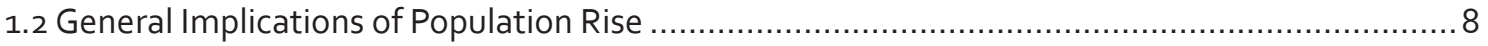

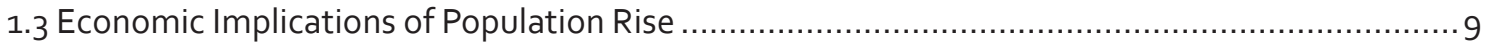

2. Demographics with a $21^{\text {st }}$ Century Consideration ......................................................... 10

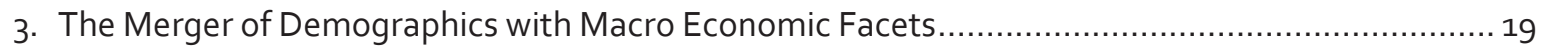
3.1 Government Budget Constraints of Growing Populations ........................................ 21

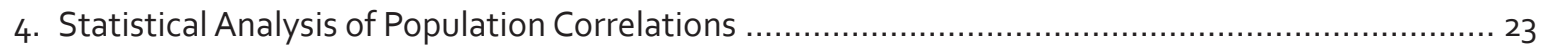

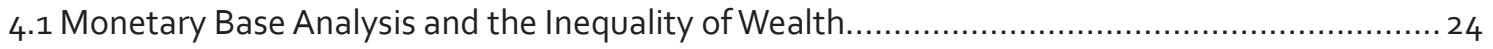

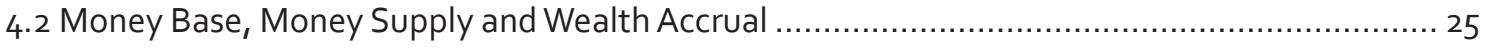

4.3 GDP, Inflation and Debt Correlations to Population Growth..................................... 28

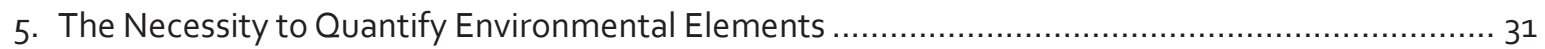

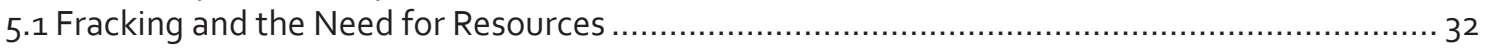

5.2 Environmental Damage and Overpopulation ...................................................... 34

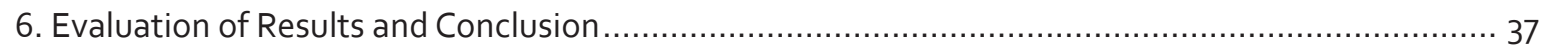

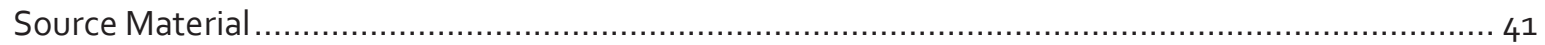




\section{Economic Implications of Growing Populations and Changing Demographic Structures}

\author{
Christopher NORTH* \\ *26 Woodgreen, Woodcote, Reading, \\ Berkshire RG 80QQ, United Kingdom
}

Supervision by Erich W. STREISSLER

Received: 17.06.2014, published online: 15.12.2014
Mag. Christopher North started his University education at the University of Exeter, England, graduating in the fields of Econometrics and Statistics. He subsequently completed his Master of Science degree at the University of Vienna in 2013, specialising in Corporate Finance and International Management. He is currently employed by Invesco Perpetual as an Investment Risk Analyst in England.
The purpose of this paper is to ascertain whether, and to what degree, increases in population levels affect economic indicators. The foundation of this study will be anchored through clear definitions of the significant economic variables, as well as an analysis regarding rising populations. The latter will be clarified by scrutinising the development of birth and mortality rates, longevity and net immigration. In order to conduct a study with a tangible benefit, data from leading global institutions, such as the United Nations, European Union, The World Bank and national government websites will be extracted, alongside publications from experts in the field of demography and population growth. These will provide a sound foundation for this paper, which will consider global scale implications of the forecasted population trends. As arguably the most powerful nation, America will be the subject of a more narrow examination.

The concept behind this publication and the necessity for a more precise report is the excessive ambiguity in today's news relating to the economic climate, including the road to regaining prosperity. In fact, it is the author's vehement belief that the impact of population size is grossly underestimated when forecasting future economic scenarios. Furthermore, it is a topic which is neglected due to its potential offence towards the freedom of reproductive choice. Nevertheless, this controversial topic must be confronted at some stage, as natural resources and their replenishment can only support a finite number of humans.

This paper will not only investigate population growth and its implications, but will also turn its at- tention towards the inverted pyramid demographic structure, discussing its relevance and proposing a modern revision of the diagram. Applying current population trends to an updated demographic structure will then facilitate a suitable medium to long term population prognosis. The author believes this is relevant because modern medical research, nutrition and family planning have improved to such a degree that population pyramids need to be updated accordingly.

The first and the predominant hypothesis of this paper is that rising populations act as a quasi-independent variable which have a significant impact on economic variables. In particular, financial factors such as inflation (through supply push and demand pull theories), pension funds, national debt, interest rates, raw material prices (including basic necessities such as land and water), energy prices, government fiscal policy (including budget breakdowns), unemployment levels, boom/bust cycles and aggregate demand will be considered as dependent variables which are either directly or indirectly affected by rising populations. A statistical analysis will be conducted to ascertain the correlations between population growth and these variables.

In addition, the aim of this paper is to bring to light the ramifications on social and environmental elements. Whilst this paper focuses predominantly on economic factors, a supplementary section will be included to demonstrate possible developments should the trend of accelerating population growth proceed. Although the author cannot deny that future soci- 
al and environmental problems could be alleviated through technological progress, the impact of humanity today can be mathematically quantified and extrapolated. In turn, if such technology were available in the future to combat our deteriorating environment, we would be able to quantify the level of damage that has been caused per year and therefore understand the measures needed to reverse any harm.

\section{Introduction: Why is the topic of Popu- lation so important?}

In 1798, Thomas Malthus published a paper titled 'An Essay on the Principle of Population'. This paper is considered the first contemplation of any individual regarding the growth of the human population on a planet of finite resources.

"Assuming then my postulata (i.e. that food is necessary to the existence of man and that the 'passion' between the sexes will remain in its present state) as granted, I say, that the power of population is indefinitely greater than the power in the Earth to produce subsistence for men."1

The notion he portrays seems perfectly logical - humans will at some point need to curb population growth in the face of a fixed resource base or face starvation. The second and more important insight that Malthus gives is his assumption of population growth as a geometrical function. Simply put, the more people there are, the greater the potential for higher growth, and indeed this is a particularly impressive notion in 1798, as his prediction is very close to how the last 200 years have unfolded. Nevertheless, Malthus probably assumed that the problem of population growth would have had a more short term implication, due to his inability to foresee the industrial age and its impact on agricultural yields. Indeed, he did assume that by today the ratio between population and agricultural yield growth would have risen to a 512:10, (assuming agricultural growth to be an arithmetically growing function $)^{2}$ which turned out to be wide of the mark. In fact, it was impossible at the time to assume the rapid implementation of the intensive farming measures that alleviated any potential food shortage, and therefore his ideas

1 Thomas Malthus, "An Essay on Population 1798", p. 4.

2 Thomas Malthus, "An Essay on Population 1798", p. 8. were quickly marginalised. ${ }^{3}$ Nonetheless, the growth of the human population over the last century has been so relentless that it probably would have taken even Malthus by surprise. During the twentieth century, the successful techniques and accomplishments in the fields of medicine, sanitation and education have allowed humans to steadily increase their life spans and prevent infant and mother mortality. Furthermore, individuals in the western world also have access to the better food and technology, which can prolong the number of years available for people to procreate.

Today's media often concerns itself with the socioeconomic symptoms of overpopulation, rather than the root cause of it. We consider unemployment and population growth in real terms rather than nominal ones, which would only be considered equal in a market when the net government contribution in unemployment benefits equals the proportional sum of the taxes paid by employed citizens which went to the aforementioned people. If this were the case, nominal and real values would incorporate little unmentioned information. However, as proven by North (2013), this is far from the case, and in fact the government is required to assume the extra economic burden per unemployed person of roughly $\$ 7,000$ per year. As a result, unemployment figures which are traditionally covered in real terms (and vary only on small scales) hide the added strain on governments over time as population size rises. The need for increased coverage in this topic would therefore tackle the inherent problems of rising demands required to cover the basic needs of a growing population, under the constraint of the planet's finite resources. It would also open up the debate for social security reform and the actual performance of job creation measures. A prognosis for future government expenditure on a multitude of areas, including health care, education and social security, should also evaluate the actual number of people covered, rather than the real value.

So how can we measure the true impact of population growth when there are so many intertwined variables? It is in fact a very difficult task, though it is possible to measure trends and observe how well correlated such trends are to population size. One

3 Chantal Lyons, "The injustice of Overpopulation", The Huffington Post. http://www.huffingtonpost.co.uk/chantal-lyons/ overpopulation-injustice_b_2641385.html 
example of this, as mentioned above, is the increase in government expenditure on education compared with the population growth of those who are recipients of the educational system. My intuition is that the latter is rising proportionally faster than the former. An expansion of this would also analyse the trend of government pension expenditure in contrast with the number of people who have exceeded the national retirement age.

Returning to the chapter question, the quantitative analysis of population growth, though important, has nothing to say when considering the social cost of an area with high levels of unemployment, which is inherently tied to antisocial behaviour, higher levels of crime, and degradation of both urban and rural areas. To summarise, population growth formerly created traditional concerns on food and land allocation, which have now stretched to consequences on unemployment levels and national economic health, as well as quality of life indicators through education and pension expenditures.

\subsection{A Consideration of Historical and Current Population Size}

The importance of population as a topic becomes more profound as our numbers reach critical levels and the rate of population growth rises to the point where sustainability becomes an issue. The diagram below depicts the dramatic population rise since Malthus made his predictions over two centuries ago, and clearly shows the acceleration of the last 50 years. Considering that the previous generation had a global population of under a quarter of what it is today and the change in living conditions at that time, the significance of this growth cannot be underestimated.

Figure 1 below shows a world population representation together with a future prognosis of population size. Table 1 shows the current population of the world's most dominant countries, as well as a net yearly population change which includes current migration trends. All of this data was retrieved from the US Central Intelligence Agency (CIA) website and a net yearly population change per 1000 people was calculated to demonstrate where population increases are most likely. Both seem to indicate a continual rise in population growth, although the figure 1 implies a slowdown in growth and peak of population size by the second half of the $21^{\text {st }}$ century.

When examining the statistics further, a few alarming notions arise which suggest that the prognoses are completely counterintuitive. The U.S Census Bureau International Data Base information echoes the United Nations excerpt above with its own assumption of a 'great deceleration' in population growth. In

Fig. 1: Source: United Nations Population Division

Population Growth and Future Estimates

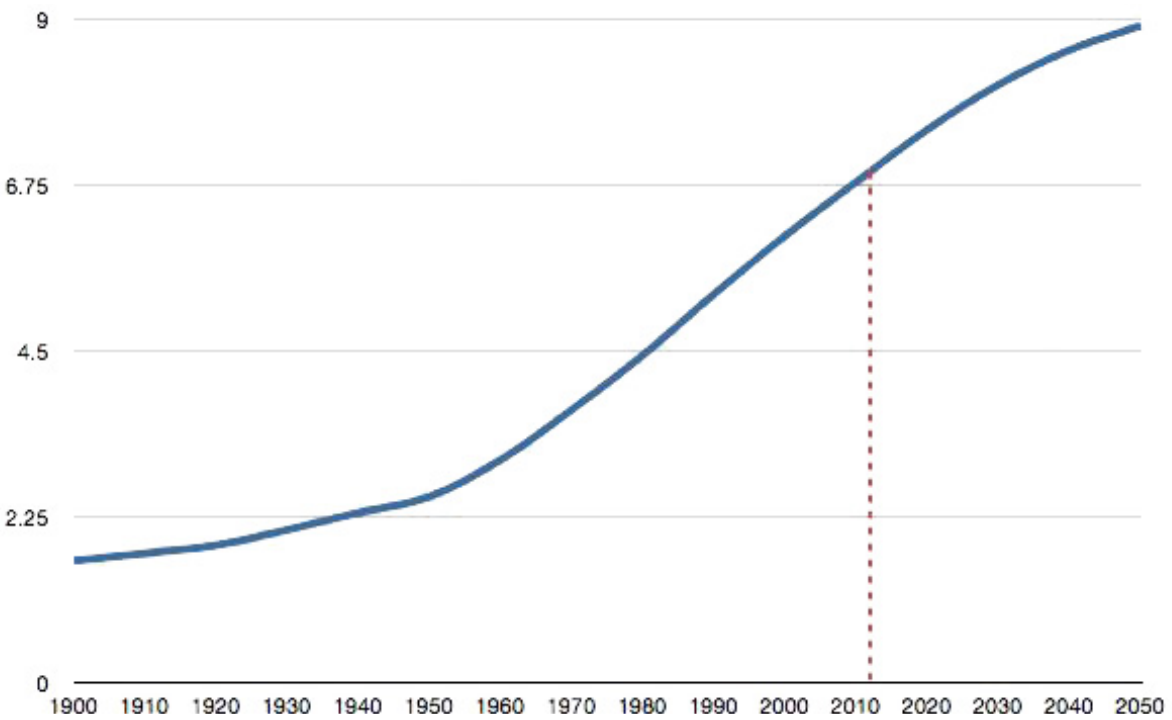


Table 1: Demography of Developed Countries - Source: CIA World Factbook $2013^{4}$

\begin{tabular}{|c|c|c|c|c|c|c|}
\hline & China & Germany & India & Japan & United States & United Kingdom \\
\hline Population (2013 Estimates) & $1,349,585,838$ & $81,147,265$ & $12220,800,359$ & $127,253,075$ & $316,438,601$ & $63,395,574$ \\
\hline Birth Rate (per 1000 population) & 12.25 & 8.37 & 20.24 & 8.23 & 13.66 & 12.26 \\
\hline Mortality Rate (per 1000 population) & 7.31 & 11.17 & 7.39 & 9.27 & 8.39 & 9.33 \\
\hline Net migration Change (per 1000 population) & -0.33 & 0.89 & -0.05 & 0.00 & 3.64 & 2.57 \\
\hline Net Yearly Population Change & 4.61 & -1.91 & 12.8 & -1.04 & 8.91 & 5.5 \\
\hline
\end{tabular}

fact, it forecasts world population growth between 2049 and 2050 to increase by 43.169 .270 people. This level is roughly on par with the nominal rise in population in 1951, when the population was under $25 \%$ of the 2049 forecast. The question which arises is simple; "assuming a century of continuous improvements in the field of medicine, is it at all likely that a population of 9 billion would have the same number of children as one of just over 2 billion?" Obviously not! To be fair, demographics also plays a role in this scenario, however the author finds it highly unlikely that the average age of the population would have risen to such an extreme that the majority of the population would have passed child bearing ages. Similarly, the prediction of growth deceleration by over $50 \%$ in the next 20 years, as forecast by the same U.S Census Bureau report, seems more a hopeful prediction rather than a realistic observation.

So what is the basis for this prediction? The reasoning for the projection of a deceleration in population growth was clarified by the 'United Nations Population Division, Population Estimates and Projection Department' press release on $13^{\text {th }}$ June, 2012, citing the following:

"GIVE OR TAKE A BILLION - Most results presented are based on the UN's medium variant projection, which assumes a substantial reduction in the fertility levels of intermediate - and highfertility countries in the coming years. For these countries, it is assumed that the pace of future fertility decline will be similar to that observed for other countries, mostly in Asia or Latin America,

4 https://www.cia.gov/library/publications/the-worldfactbook/rankorder/2054rank.html https://www.cia.gov/library/publications/the-worldfactbook/rankorder/2066rank.html https://www.cia.gov/library/publications/the-worldfactbook/rankorder/2112rank.html https://www.cia.gov/library/publications/the-worldfactbook/rankorder/2119rank.html when they underwent similar declines during the second half of the $20^{\text {th }}$ century". 5

This logic seems to be severely flawed for 2 major reasons. Firstly, it failsto understand thelargeimpact of the Chinese one child policy which was implemented in 1979 in response to a famine at the time (apparently offsetting 400 million people today), as well as the pressure by the Indian government in 1977 to cut birth rates by offering cash incentives for sterilisation procedures (up to 8 million were performed). The latter practice is still offered today, especially in the high population growth region of Rajasthan, where cars and TV sets are also offered for 'sterilisation volunteers". ${ }^{6}$ These two countries represent a large majority of the sample group being analysed by the UN report, therefore resulting in an underestimation of overall population growth. Secondly, the area in question was subject to the 2 largest war casualties since 1950, namely the Vietnam War (1965-1975) and the Chinese Cultural Revolution (19671976), each of which claimed more than 2 million lives. To use this region during a time of great unrest with large casualties as a proxy for extrapolation for future population growth is no less than fallacious.

As a retort to this prognosis, this paper has determined it's own future population estimate, derived solely from extrapolation and the logic that 'the more people there are, the faster population levels can rise'. If the yearly average rate of growth is taken from 1950-2013 and then extrapolated, we can observe the predicted population, given a historical growth rate, and quantify the difference between this result and the UN and U.S predictions. This is displayed in Figure 2, and shows

$5 \quad$ United Nations, "World Population Prospects: UN Press Release". esa.un.org/unpd/wpp/Documentation/pdf/ WPP2012_Press_Release.pdf

6 BBC South Asia News, "India: Rajasthan in 'cars for sterilisation' drive", $1^{\text {st }}$ July 2011. www.bbc.co.uk/news/ world-south-asia-13982031 
Fig. 2: Comparison Between World Mean Population Estimate and UN World Population Forecast

Comparison Between World Mean Population Estimate and UN World Population Forecast

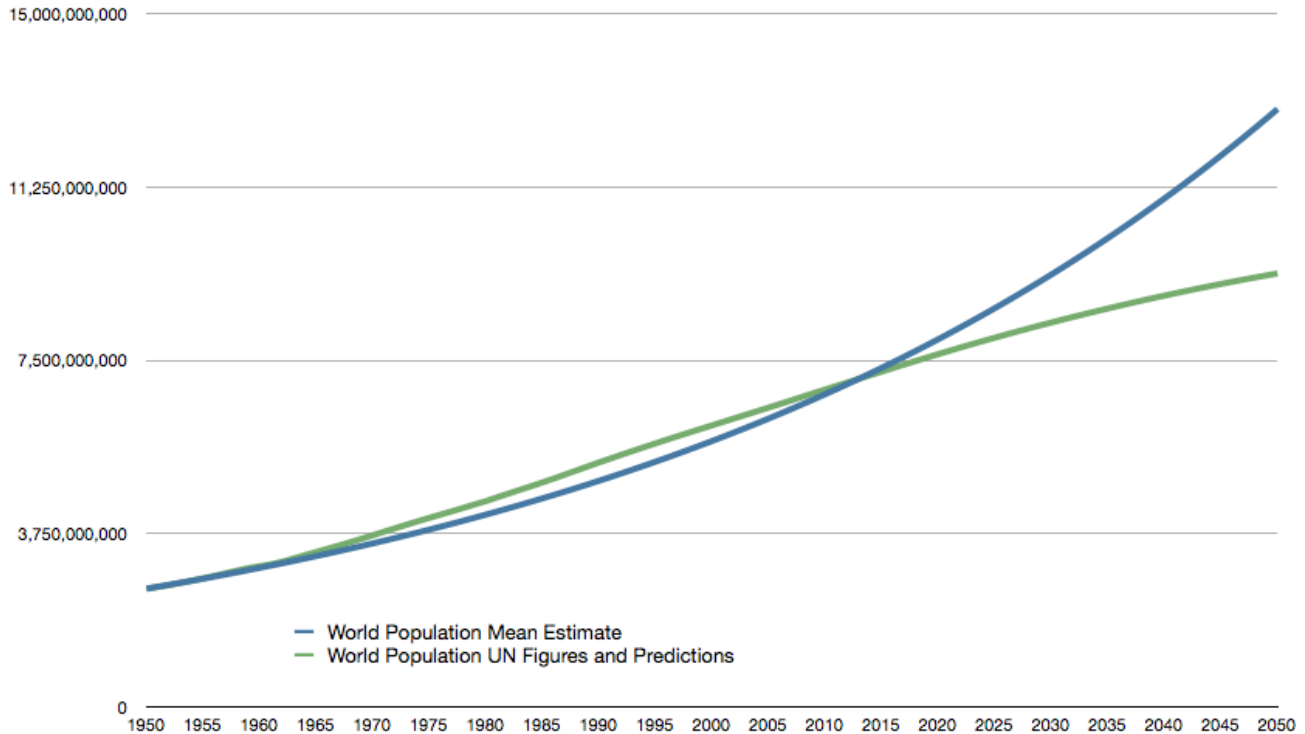

an estimated population of just under 13 billion $(12,934,192,764)$ in 2050 if historical mean population growth continues, compared to the UN's prognosis of around 9 billion.

The mean estimate extrapolates additional growth increases due to more people on the planet, and therefore cannot even be thought of as an overestimate. Instead, it seems a more plausible forecast than one which anticipates an incredible decline in growth rates without any form of world famine, war or natural catastrophe. To conclude this point, the United Nations estimates may be completely erroneous and in fact the population may continue at increasing rates. We are currently at the steepest acceleration of our population, with an average of 2 people added to this world each second ( 4 children are born and 2 people die per second), 200.000 a day, or 80 million a year. ${ }^{7}$ By 2050 , the population is expected to grow by 2.3 billion, according to the UN's conservative figures, which represents the current population of Europe, Africa, North and South America combined. ${ }^{8}$ A significant slowdown is therefore difficult to foresee. The obvious longer term implication of population growth is sustainability. John Porrit, Chair of the

7 National Geographic, "Special Series: 7 Billion". http://ngm. nationalgeographic.com/2011/01/seven-billion/kunzig-text

8 David Attenborough, Documentary: "How Many People Can Live on Planet Earth".
United Kingdom Sustainable Development Commission, was interviewed in March 2014 as saying "I find it staggering that it (population) is still downgraded as an issue. There is a sense that it is somehow politically incorrect to talk about population. Ignoring population strikes me as the biggest own goal that the environmental movement has ever scored." ${ }^{\prime}$

Alan Weisman, author of the book Countdown, discussed the topic of population growth on live television, citing the use of nitrogen fertiliser as the reason our population has been able to expand to current levels and the environmental damage which has now been observed from it:

"Now we pull nitrogen fertiliser chemically out of the sky using fossil fuels and slather it all over the ground. When we started doing that commercially there were 2 billion of us. Without nitrogen fertiliser, $40 \%$ of us wouldn't be here. Now that we know that nitrogen fertiliser has its downsides; it's screwing up the oceans, our waterways and it's sterilising soils, and all these crops are being force fed with chemistry. If we weren't doing that, I'd say 2 billion (people) ight be the optimum."10

9 Youtube Link, "Population Matters Online". https://www. youtube.com/watch?v=2H0pOlrXSyI\&list=PL811CD932F93 $6221 \mathrm{~B}$ 
As a result of the problems cited by these two sources, population is an essential topic today and will be discussed in the proceeding chapters.

\subsection{General Implications of Population Rise}

Now that the degree of world population growth has been analysed, this paper will concentrate on the implications of such a rise. The most high profile critic of human overpopulation is Sir David Attenborough, a reporter for numerous nature documentaries and member of an organisation called the 'Optimum Population Trust'. Although currently in a minority, Sir David has gone on the record to state that 'population figures were frightening', ${ }^{11}$ even calling human pulation growth 'a plague on the planet and a detriment to the environment'. ${ }^{12}$

David Attenborough cites 3 major environmental aspects in his recent population documentary which population growth has affected: Water, Land and Energy. All of these are scarce resources which can also be quantified economically - Land through house and food prices, water through water prices, and energy through costs of electricity and heating. All of these have risen perpetually, however it is rash to solely link price rises (especially energy) with population growth, due to the impact of other variables such as inflation, accessibility, transport etc. Nevertheless, we can consider a logical economic trend by noticing that all of the resources mentioned are basic human requirements in scarcity. Simple economics would hence dictate that rising populations would push the prices of finite resources sequentially higher (Figure 3), especially those resources which are essential for life. The first four months of 2014 have shown a $17 \% \mathrm{r}$ rise in S\&P GSCI agricultural and livestocks index, primarily caused by climate change. ${ }^{13}$

Despite this, the author does not believe that price hikes are a likely outcome in the very near future. The increases in such prices will be gradual and medium term rather than sudden sharp price shocks.

The fact though remains that although humans are currently living beyond the ability of the planet to

Fig. 3: Increasing Populations with Finite Resources - Economic Theory

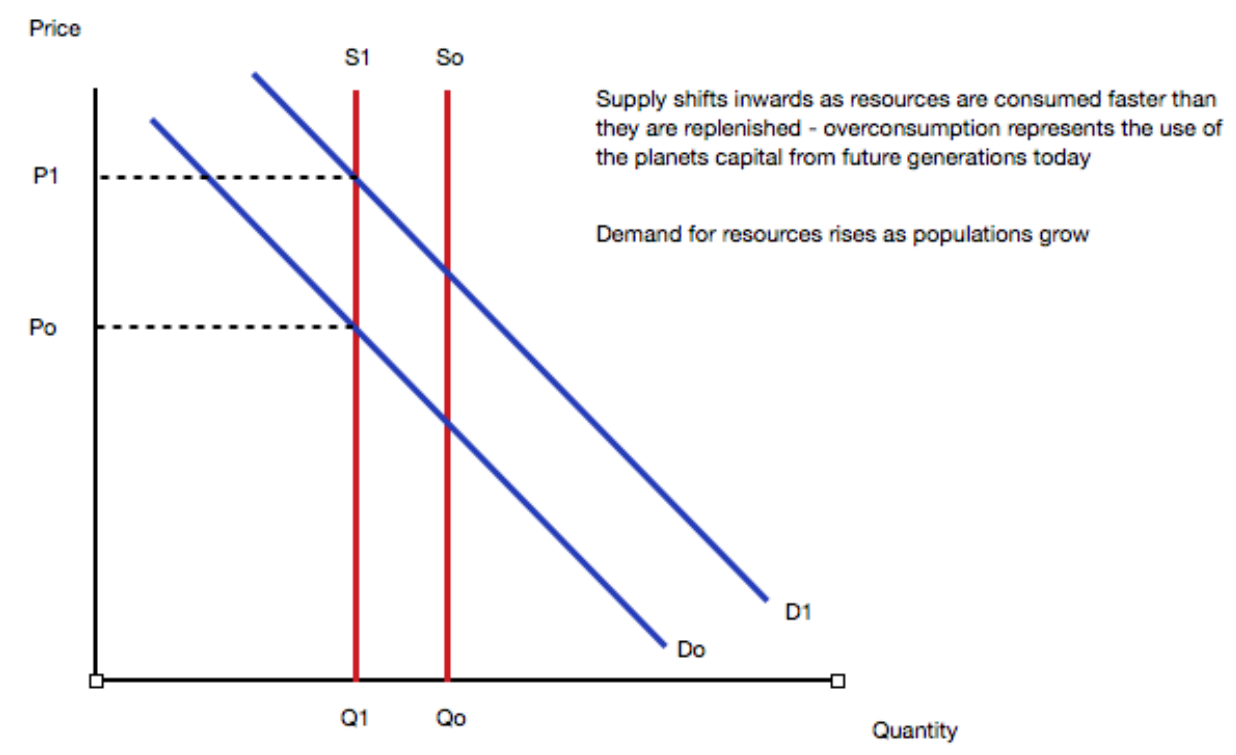

11 BBC News Website, http://news.bbc.co.uk/1/hi/7996230

12 Metro Newspaper, http://metro.co.uk/2013/01/22/sir-davidattenborough-human-beings-have-become-a-plague-on-theearth-3361381

13 Emiko Terazono, "Climate extremes inflate food prices", Financial Times Online. http://www.ft.com/cms/s/2/5c4500fca518-11e3-8988-00144feab7de.html\#axzz2zMBDB7JI 
replenish its natural systems, there are still resources to be exploited, albeit at a lower and costlier rate. An example of this was explained by Danny Dorling in his book 'Population 10 billion', which asserts that although water consumption in the UK has dropped by $5 \%$ between 2003 and 2010, net demand for water still continues to rise. ${ }^{14}$

However, it is noticeable that as necessities become scarcer, we can expect the prices of goods such as water, food, housing and energy to increase. ${ }^{15}$ The Guardian newspaper reported in November 2013 that energy bills have risen by $37 \%$ in 3 years, or 8 times the rate of earnings, which shows the squeeze of rising prices on households real personal disposable income. ${ }^{16}$ This seems to suggest a continuous trend and effect of scarce resource consumption. A further look at this effect will be covered in a latter chapter of this publication.

In a world where 1.2 billion children live in poverty ( $45 \%$ of the worlds children $)^{17}$, where only $1 \%$ of the worlds water is fresh, drinkable and actually available to us, ${ }^{18}$ and where over half of that is in catastrophic decline or overuse, parameters such as population must be considered. United Nations secretary general Ban Ki-Moon described the world in 2011 as one of 'contradiction', with "luxury and extreme poverty". ${ }^{19}$ Unfortunately, current issues are only likely to become exacerbated with an increasing population, and indeed we are already anticipating the consequences of being so reproductively successful - in $200725 \%$ of world fish stocks were overexploited

14 Danny Dorlin, "Population 10 billion". Reposted in the Huffington Post by Chantal Lyons: Gambling on our Future:Overpopulation and Overconsumption. http:// www.huffingtonpost.co.uk/chantal-lyons/overpopulationoverconsumption_b_4049398.html

15 The Guardian Newspaper, "Dramatic decline in industrial agriculture could herald 'peak food' ". http://www.theguardian.com/environment/earth-insight/2013/dec/19/industrialagriculture-limits-peak-food

16 Guardian online, http://www.theguardian.com/money/2013/ nov/16/energy-prices-rise

17 UNICEF Website, "State of the Worlds Children".

18 David Attenborough, Documentary: "How Many People Can Live on Planet Earth".

19 UPI News, "7 billion people is a 'serious challenge'", October $31^{\text {st }}$, 2011. www.upi.com/Top_News/ US/2011/10/31/7-billion-people-is-a-serious-challenge/UPI73301320046200/\#ixzz2mw98ZcWz or fully depleted, ${ }^{20}$ with the anticipation of no fish at all in the sea by 2050..$^{21,22}$ The Food and Agriculture Organisation reported in 2010 a loss in world forest cover by 13 million hectares a year, ${ }^{23}$ and this is also likely to increase. If fact, as quoted in the 2010 Global Forest Resource Assessment;

The five most forested countries (The Russian Federation, Brazil, Canada, the United States of America and China) account for more than half of the total forest area $(53 \%){ }^{23}$

Given the well documented deforestation in Brazil, this is quite a worrying statistic. A summary of population growth implications are therefore listed as follows:

1) As population levels rise, resources will become scarcer, and their allocation will become more unequal. Prices of resources which are considered 'basic' will also rise, due to the exhaustion of resources such as arable land, fresh water and nonrenewable energy.

2) House prices, though susceptible to economic boom/bust cycles, will continue to rise in the long run.

3) The availability of most forms of food will become scarcer and therefore more costly due to our current overconsumption.

\subsection{Economic Implications of Population Rise}

Economic implications are harder to predetermine, as many variables contribute in tandem to influence economic indicators. Nevertheless, in addition to the more easily explained connections between population growth and traditional economic variables, this paper will perform a more complicated analysis on government budget implications, which the author

20 Kjellrun Hiis Hauge, Belinda Cleeland and Douglas Clyde Wilson, "Fisheries Depletion and Collapse", International Risk Governance Council. http://irgc.org/wp-content/uploads/2012/04/Fisheries_Depletion_full_case_study_web. pdf

21 Richard Black, "Only 650 years left for Sea Fish", BBC Science/Nature. http://news.bbc.co.uk/1/hi/6108414.stm

22 End of the Line Documentary, endoftheline.com

23 United Nations Food and \& Agriculture Organisation, Global Forest Resource Assessment 2010. http://www.fao. org/docrep/013/i1757e/i1757e.pdf 
believes experiences unobserved impacts via population growth.

The predominant variables which best explain the state of an economy are inflation, money supply, GDP growth, unemployment, the current account and government debt level. An added state of ecological decline is starting to filter into economic literature, though the difficulty in quantifying environmental degradation restricts a practical analysis. The author postulates that as populations grow, inflation and GDP grow at a faster rate, whilst unemployment and government debt worsen (or experience pressure into greater deficits) as population size rises._If these hypotheses are proved to be valid, then the concept of population should be increasingly incorporated into modern economic theory and can be used as an indicator for future economic states. As a result, methods of financial forecasting on a macro scale would need to be adapted to include the population variable.

The analysis of government budgets, and ascertaining the influence of population growth, is a far more difficult undertaking. What the author wishes to highlight is the growing proportion of expenditure allocated towards social security, medicare, medicaid and pension payments, at the expense of infrastructure, education and environmental protection.

The structure of this paper will proceed as follows. The next chapter will consider the demographic structure of countries and attempt a review of the inverted pyramid (figure 11) to a more modern approach. This area is relevant when forecasting government budgets, pension expenditures and future tax levels. The theory described by North in his 2013 publication 'Financial Crisis Forecasting - Causes, Effects and Systemic Factors Influencing Financial Crises' will also be used as a basis for economic forecasting.

Once the major economic parameters have been covered, the paper will return to a quantitative approach regarding the more general variables described in subsection 1.2, in particular food and water prices, which are heavily influenced by population growth. This will conceivably shed a more arithmetic approach to an otherwise conjectured issue. The addendum attached to this paper will express the authors' opinion towards the social ramifications of overpopulation.

\section{Demographics with a $21^{\text {st }}$ Century Consideration}

The study of demographics examines population composition and quantifies various subsets, whether it refers to age groups, gender, race, ethnicity, languages etc. Data derived from demographics is especially vital for governments when discussing issues such as workforce allocation, net migration, pension funds and unemployment percentages, and are often hot topics in national and general elections.

Demographic changes are affected by health, education, availability of medicine, country specific life expectancy, economic prosperity, availability of contraception, religion, socio cultural norms and net migration. Trends of each of these variables in turn dictate policy aimed at continuous improvement of these variables.

One of the most widely used depictions of population structures is the population pyramid, which breaks down the population into subsets of age and compares them with one another. The result of this is the capacity to understand whether a country's population structure is ageing too fast or too slow, and if there is a lack or abundance of young people.

As a result of the vast differentials in wealth, education levels and infrastructure, population structures of developing countries vary enormously from those of the western world. Developing countries are assumed to have populations with greater concentrations of younger and middle aged people, whereas western countries have the symptoms of ageing populations, such that larger proportions of citizens are middle aged or reaching retirement. There are downsides to both of these scenarios - in developing countries the average lifespan is lower, due to restrictions in medical care, access to the necessities of life and lack of reproductive education. Child mortality rates are also higher, and consequently families have more children to ensure that some reach maturity. By contrast, developed countries are becoming increasingly dependent on immigration to cover the tax burden of their ageing populations.

A lack of education results in people leaving school and marrying earlier, which increases the likelihood that women have children (and more of them) at much younger ages. Alternatively, an ageing population symbolises one which has a lack of young people 
in the workforce. The latter is particularly troublesome for pension funds, which rely on the premise that new workers contribute taxes to support retirees. This will be discussed further in the implications of economic variables section. In addition, when new skilled labour is lacking in western societies, it creates a gap which is filled by immigration. Whilst this is perfectly acceptable and common in western societies today, it does create a brain drain in lesser developed countries, which stunts their progression.

The figures below demonstrate the difference today in demographics between developed and developing countries, and are designed to give an insight into the development of some of the world's most powerful countries.

Fig. 4-11: Demographics Data Obtained from CIA Library - The World FactBook ${ }^{24}$

\section{Developed Countries}

Figure 4

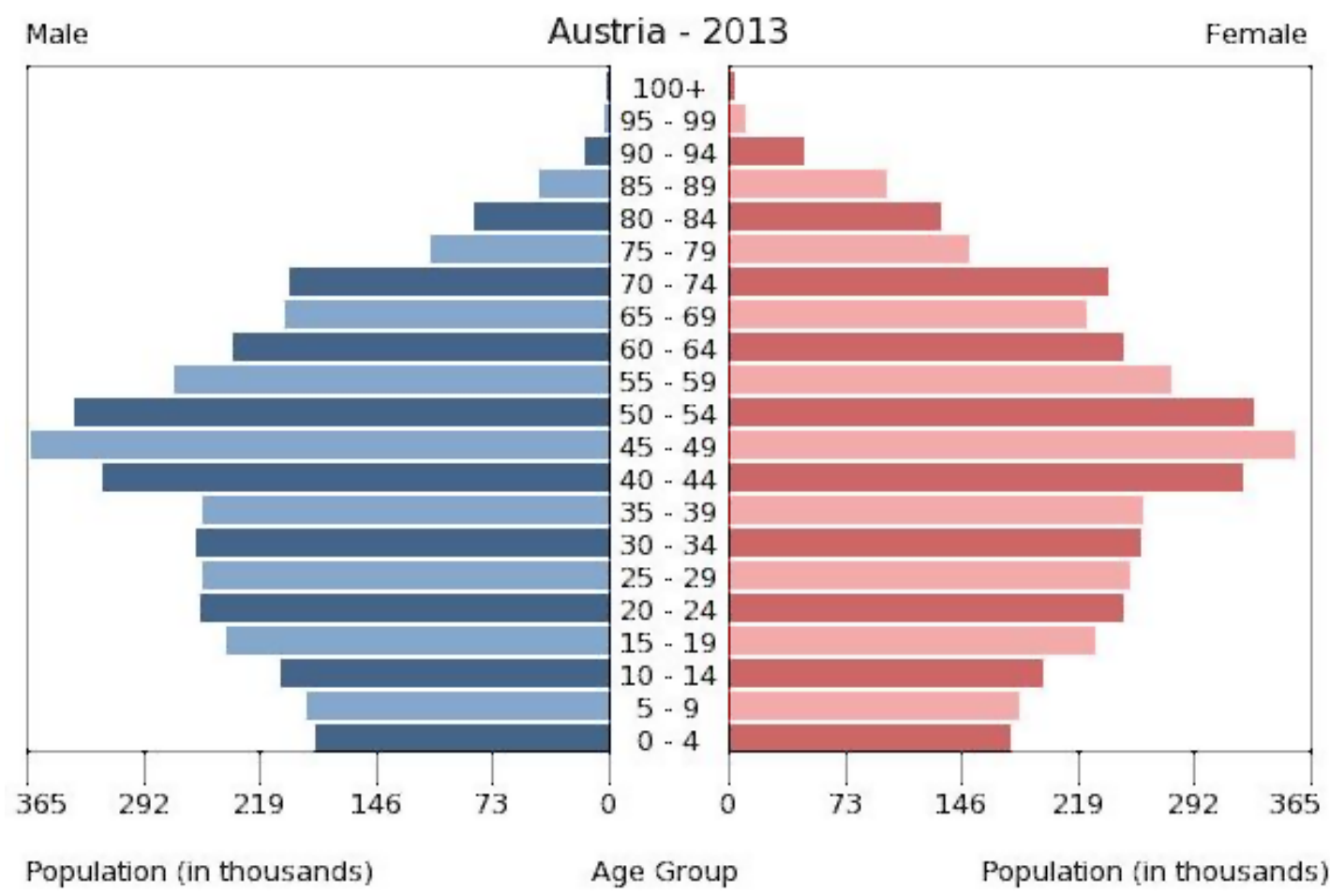

24 CIA World Factbook 2013, https://www.cia.gov/library/publications/the-world-factbook/ 
Figure 5

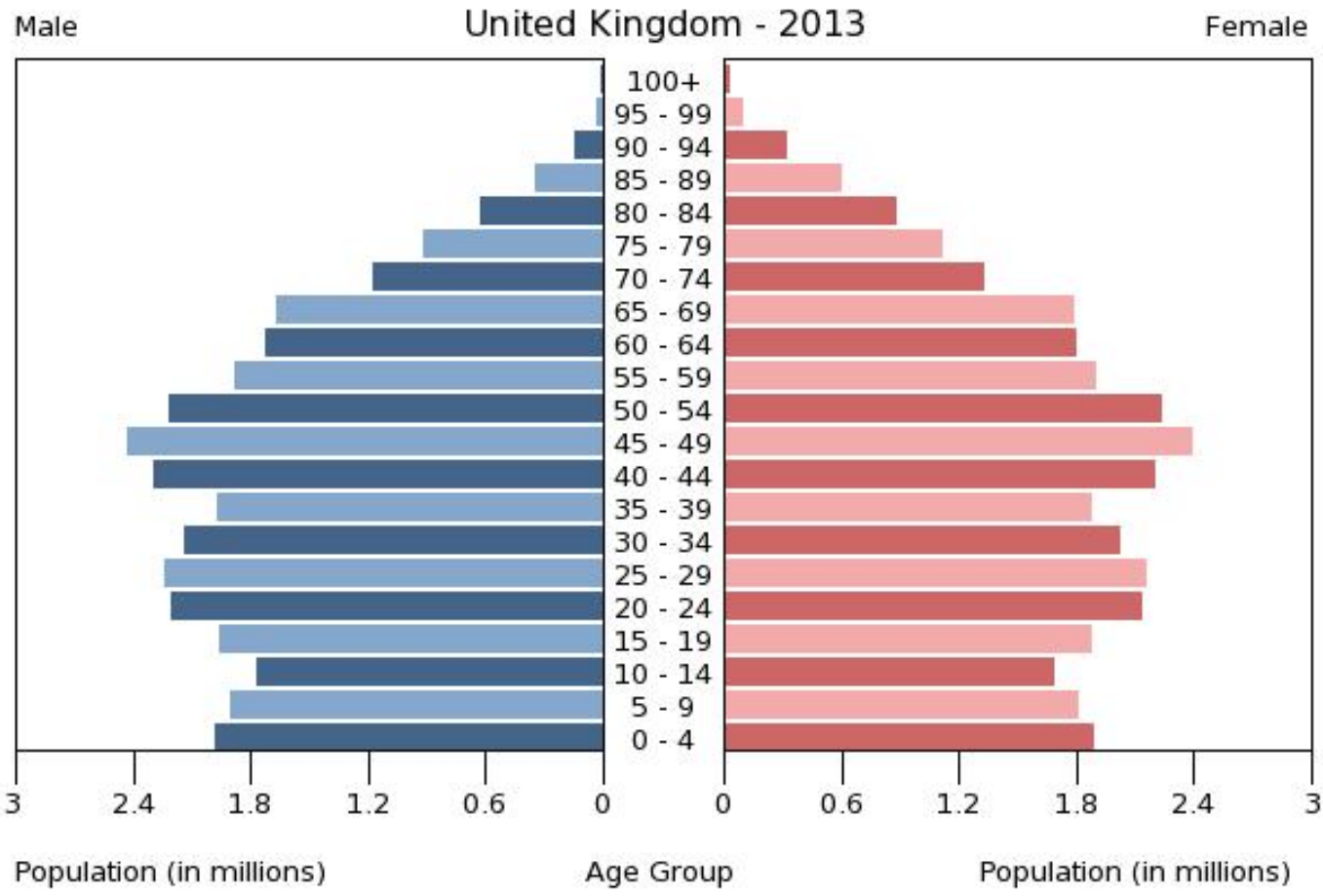

Figure 6

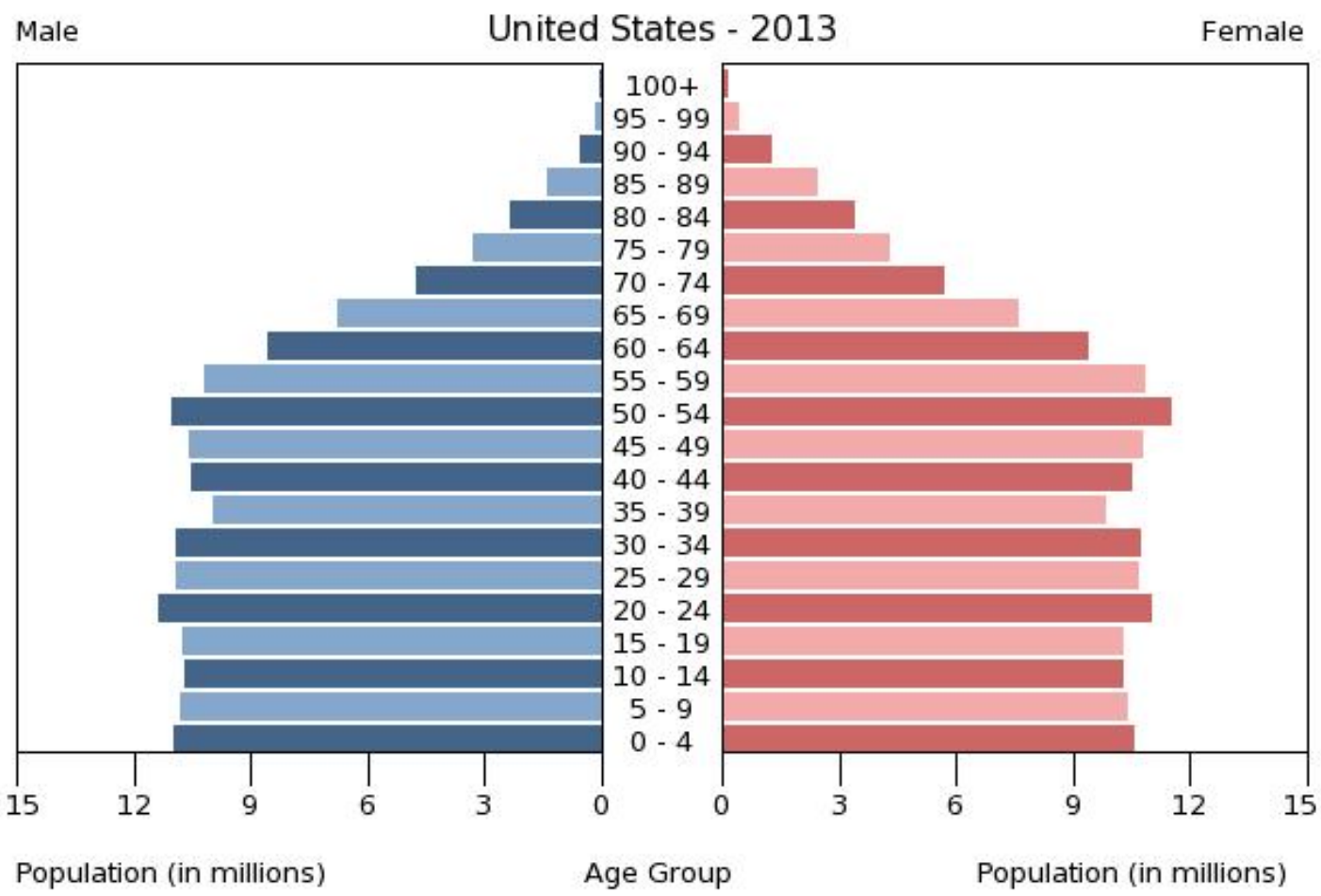


Figure 7

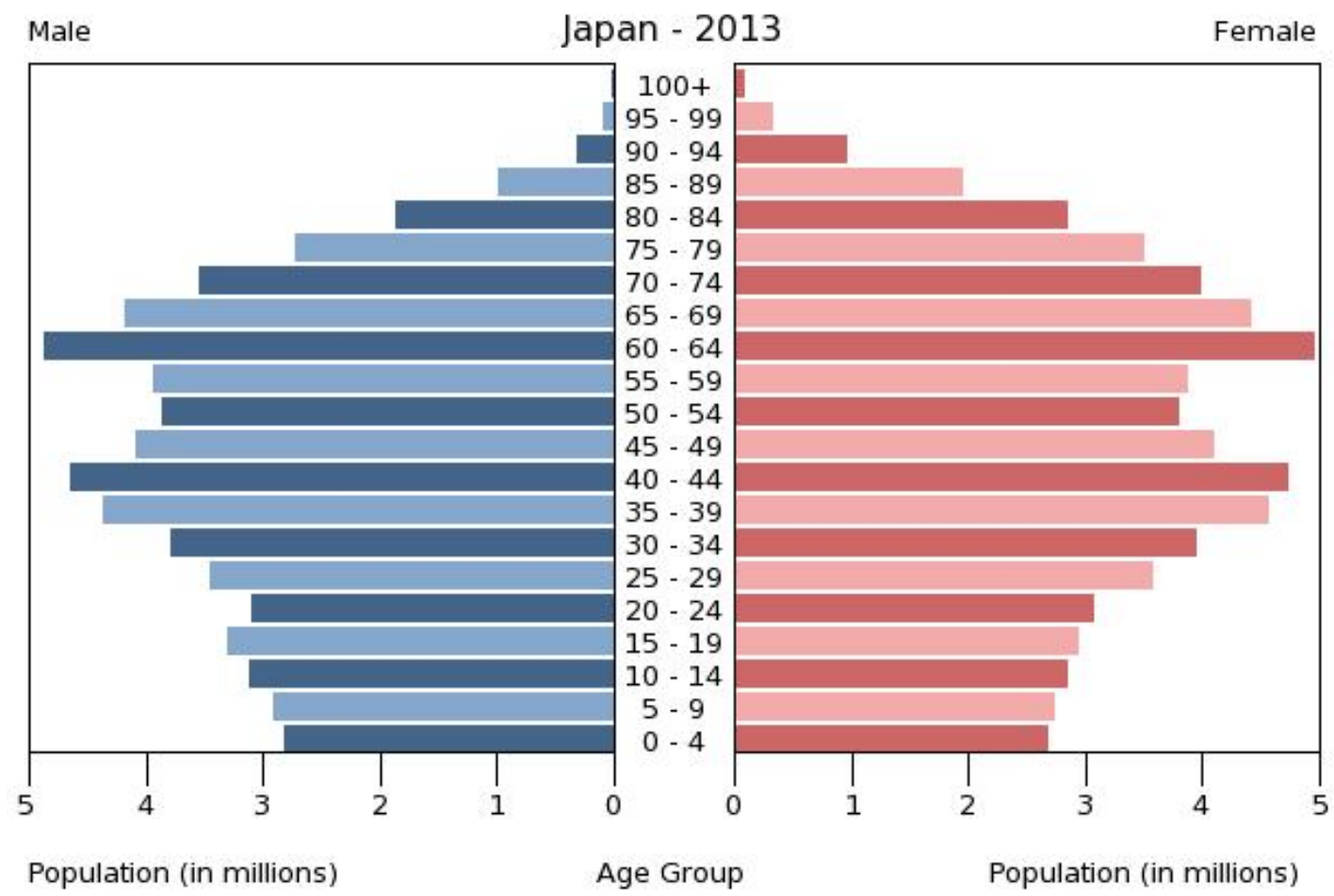

Figure 8

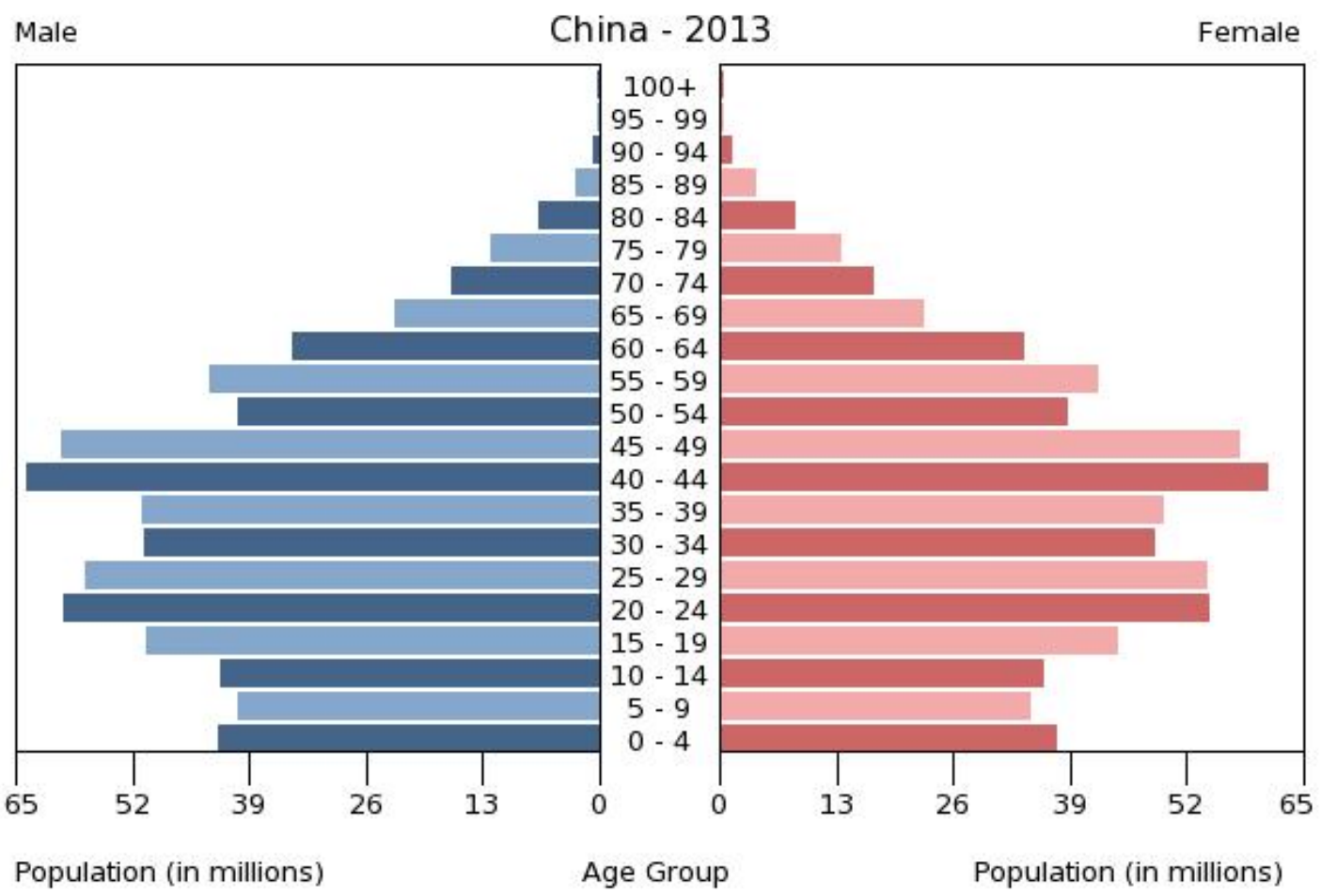


Developing Countries

Figure 9

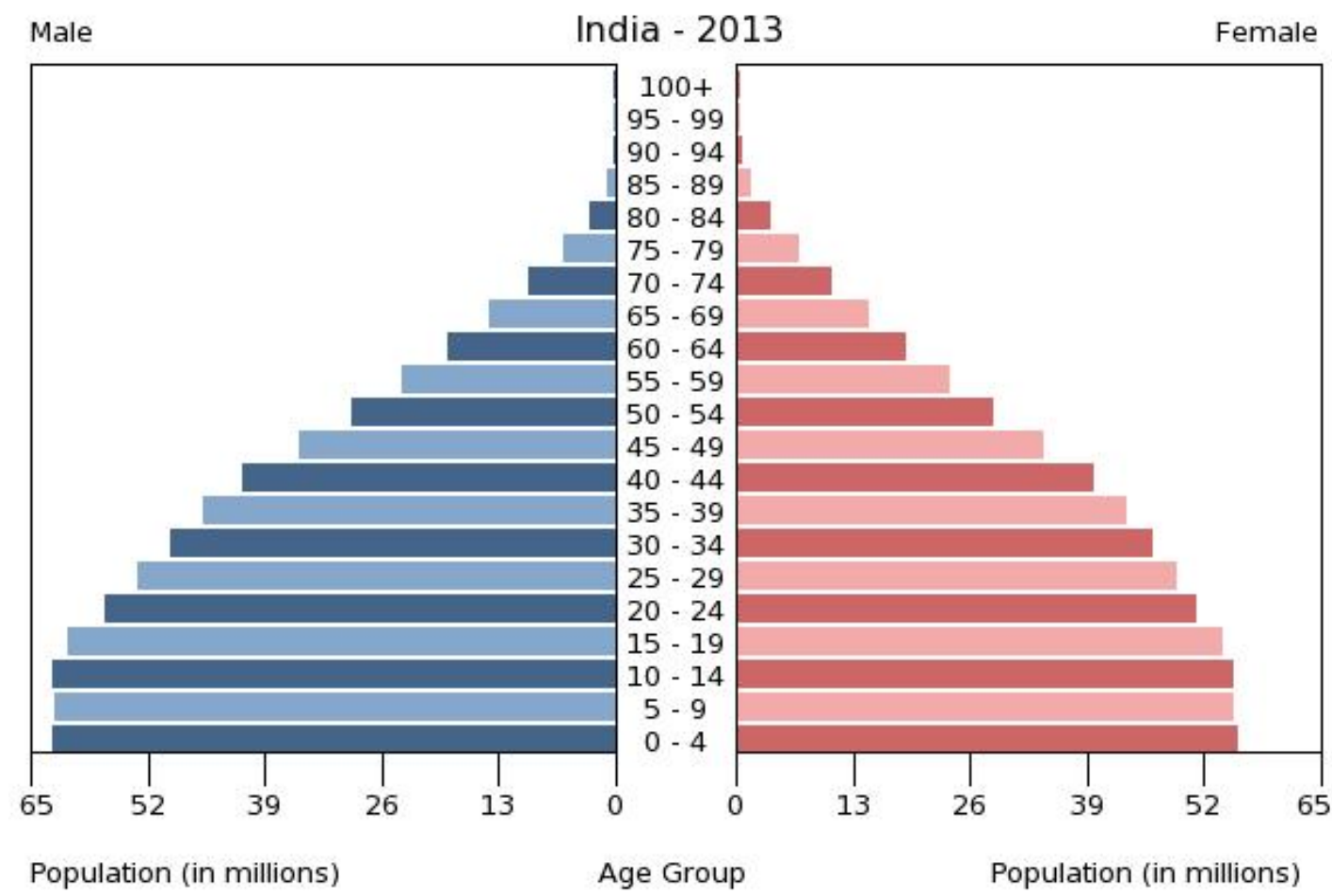

Figure 10

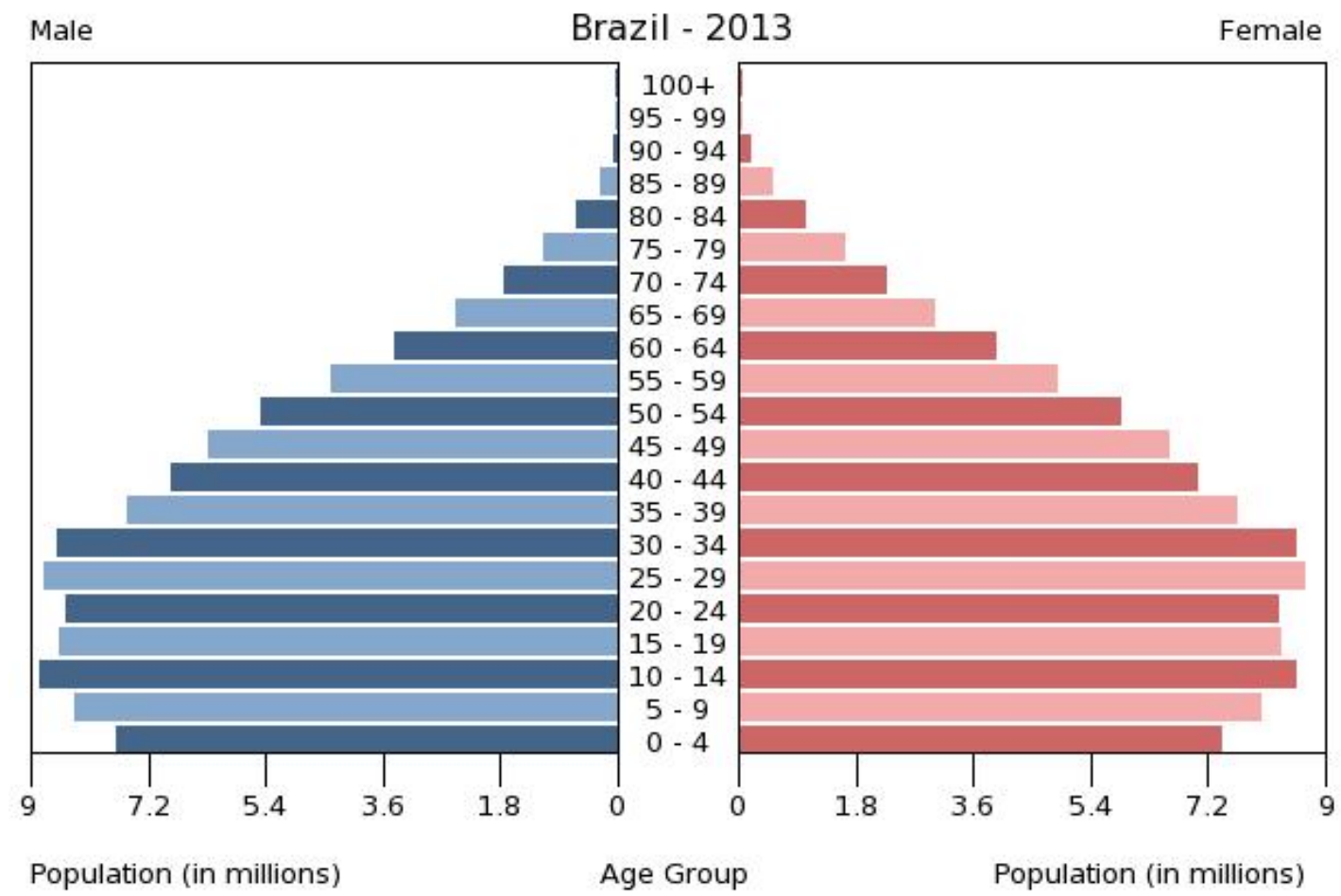


Figure 11

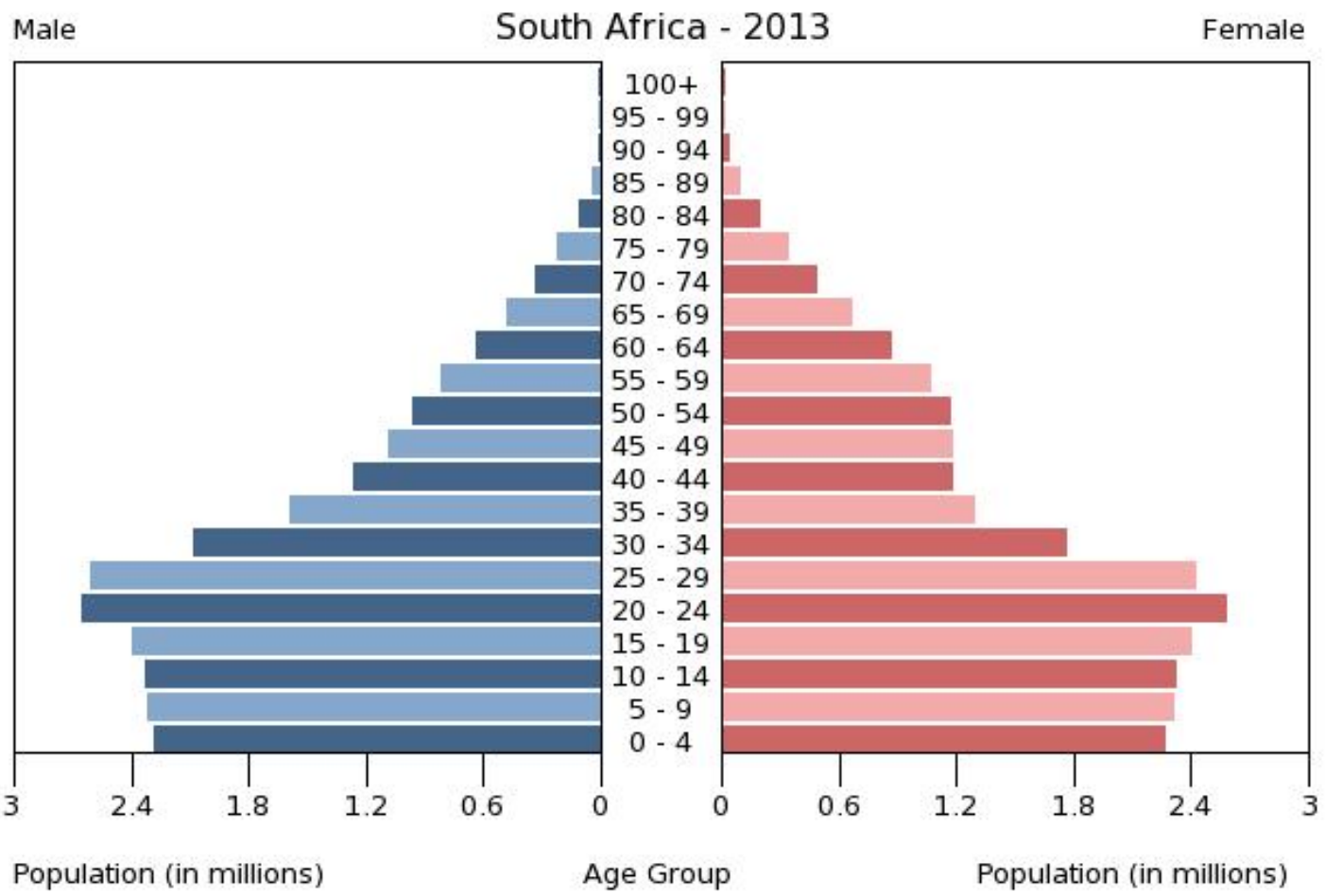

When observing these diagrams, a clear distinction between the population structure of developing and developed countries is demonstrated. What most people neglect to mention in these diagrams is the different scales of the $\mathrm{x}$-axis which are used. Naturally, regardless of the age breakdown, larger populations would exacerbate the margins between each given age group. Take for example the last two diagrams of South Africa and Brazil - it seems that the base of the Brazil diagram (people aged 0-24) is much wider than South Africa's, and nominally this is true. How- ever, if we analyse the $\mathrm{x}$ axes, we notice that Brazil's scale is 3 times greater than South Africa's.

For the purpose of clarity, a scaled representation of the population structure is demonstrated below (Figure 12). This is achieved by taking a proportional approach and scaling the South African population upward, such that it is equal to Brazil's. The result of this shows that despite what is implied by comparing the population structures, the reality of a scaled population structure is actually very different.

Fig. 12: Differences in Scaled Population Age Groups between South Africa and Brazil

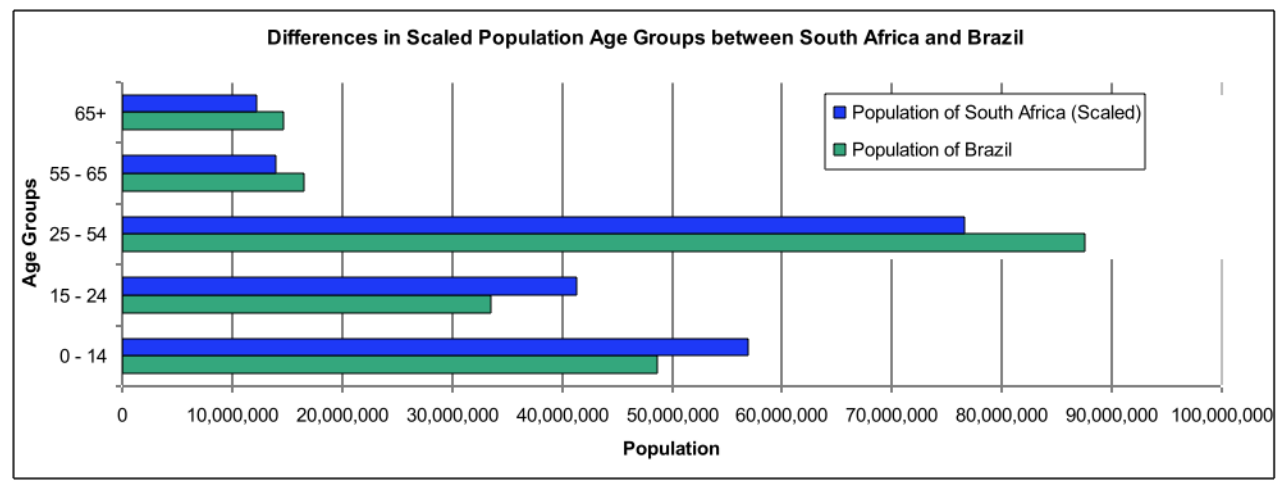


South Africa's population, though distinctly smaller, has a proportionally younger average age, which is vital when forecasting future development. To avoid this misinterpretation the author proposes that population structures should be depicted in terms of the proportions of the whole population, rather than nominally.

The second proposed alteration arises when we consider the changes in society which have occurred throughout the last half century and following the adoption of demographic diagrams. In essence, this diagram has remained the predominant method of displaying population structures. Although age group divides may change, essential information regarding their interpretations are somewhat misleading, and the implications of population changes should also be made more apparent. For example, the longevity, birth rates and retirement ages should be incorporated into such diagrams. To clarify, there is no justification for encouragingly commenting on a country's future prosperity (through its youthful population) when child mortality rates are high.

When considering the case of India, the difference between the age groups is apparent. The crucial information which should not be neglected is the development of Indian citizens' health, as it will determine the country's future prosperity. It is all too often that we look at India's population structure from a western perspective with admiration; however we must remember that this is the first generation in India which has the prospect of western style development. Furthermore, their health care systems may differ significantly from what Europeans and Americans consider the norm. As a result, there are negative aspects which must be considered. Is India's life expectancy much lower by European comparison, and if so, is it due to poor sanitation, disease, or the quality of healthcare and life? Is the birth rate likely to continue at current levels, or will it trail off? If it does indeed fall, as it is predicted to, will it cause similar or greater future problems than what Europe is experiencing now?

Moreover, the evidence suggests that countries with high birth rates are those which have the least female rights - so is it really worth celebrating India's future with respect to education levels? In every case, the empowerment of women, i.e. by giving women the ability to be educated and make their own marital and reproductive choices, has resulted in a large fall in birth rates. ${ }^{25}$ This is known as the demographic transition theory, and is often cited as the best method of creating a sustainable population as a country transitions from 'developing' to 'developed'.

The United Nations population fund 'State of the World' annual report highlights the above point, citing that despite the visible benefits today from improved female education, there is still much to be achieved. ${ }^{26}$ Whilst this is obviously beneficial for a country such as India, it may have catastrophic side effects if we fast forward to 2050 without a large decline in population growth. Considering a scenario in India where birth rates fall, a large proportion of the current 1.27 billion ${ }^{27}$ people will require funding for pensions, health care and other living necessities. As a result, it is an absolute necessity that not only should the current population structure be included, but the future prognosis of the next generation should be considered. By doing this, governments can better plan future economic states.

Thirdly, there is one important yet basic characteristic which links future population growth with population structures which has not been given much consideration. The author would like to highlight the factor of population density, which reflects the current number of people occupying a given landmass and the amount of land available to accommodate future growth. When considering the United Kingdom (around 70 million) and the United States (314 million) demographics, we see that despite its large (population) size, America has a far lower population density than England. In comparison with India, which has quadruple the number of people as America, population density plays an important role in determining the standard of living. ${ }^{28}$

Nevertheless, India's population continues to rise at far larger rates than those in the western world. Surely population structures which foretell a large increase in numbers should recognise these numbers relati-

25 Allianz knowledge, http://knowledge.allianz.com/?363/howfemale-empowerment-affects-population-growth

26 United Nations Population Fund, "2013 State of the World Report", http://www.unfpa.org/webdav/site/global/shared/ swp2013/EN-SWOP2013-final.pdf

27 India Online Website, Indian Population". http://www. indiaonlinepages.com/population/india-current-population. html

28 New Geography Website, http://www.newgeography.com/ content/002808-world-urban-areas-population-and-densitya-2012-update 
ve to the size of the country and population density? As of yet this is not the case, and we have become a relentlessly growing population that increasingly pressurises finite land and water resources. It could be the case that future population growth is simply not possible due to exhausted space. Consequently, the author proposes the amendment that population density should also be incorporated into the population structure diagram.

When analysing the most densely populated urban areas, it is noticeable that the majority of the top 10 cities are from Asia, and include cities with high population growth rates. They are displayed in order below:

- Dhaka, Bangladesh

- Mumbai, India

- Surat, India

- Chittagong, Bangladesh

- Hong Kong, China

- Ahmadabad, India

- Bogota, Colombia

- Medellin, Colombia

- Karachi, Pakistan ${ }^{28}$

Demographics and forecasting are linked through potential population growth, as well as the opportunities and restrictions which will be present for future generations. The future challenges will be new and restrictions on population size are something humans have never experienced before. As a result there is a need for the sustainable planning of growing populations given size and environmental constraints. For example, a potential maximum population size must be addressed at some point in the future, whether globally or country specific. The underlying questions we pose when looking at population structures today should be as follows:

1) What is the age distribution implying?

2) Can we make a prognosis for the short/medium/ long term?

3) What is the average lifespan of this population, so that a future prognosis can be made?

4) What is the distribution of males/females?

5) Can this trend continue with respect to the worlds resources?
6) What are the economic and social implications of this structure?

7) Are these trends sustainable?

In the current population structure diagrams, we lack the ability to answer the majority of these questions accurately. As a result, the author has made several alterations which provide a better graphical representation of a country's current population, the future population, and in particular how the population structure will look in 50 years (Figure 13).

Firstly, each age group for males and females are displayed in percentages rather than real numbers. The reason for this is that nominal population size is of no relevance without the land size variable, as it is impossible to demonstrate whether the specific country is overpopulated or not. As proved with the diagrams of South Africa and Brazil above, it is also misleading to use 'real' figures, because the overall distribution appears different. To compensate for this, a population density is included in the diagram. Whilst further research is required to determine what an optimal population density is, once it is ascertained we can observe very clearly if a country is likely to be overor under-populated in the coming decades. Similarly, it is worth mentioning that the population density of the Earth is just over 50 people/ sq. km (for land mass excluding Antarctica) ${ }^{29}$. In order to answer questions 1, 2 and 3, we need more information concerning the average lifespan. It is again erroneous not to include an average lifespan in demographic structures and use a one-size-fits-all approach, particularly if we are comparing the demographics of a developing country with those of a developed one. Consequently, a green horizontal line showing the average lifespan is included. The purple line is termed the mortality prognosis line, and is set for simplicity at roughly 50 years below the average lifespan line. The concept of adding this line is to show a current and 50 year population pyramid by showing where the base will be in the next half century. A prognosis of the birth rate can then add a forecasted base of the future diagram. The mortality prognosis line can of course be set at a shorter or longer term, but 50 years seems a prudent figure when we consider future demographic structures.

29 Matt Rosenberg, "Population Density". http://geography. about.com/od/populationgeography/a/popdensity.htm 


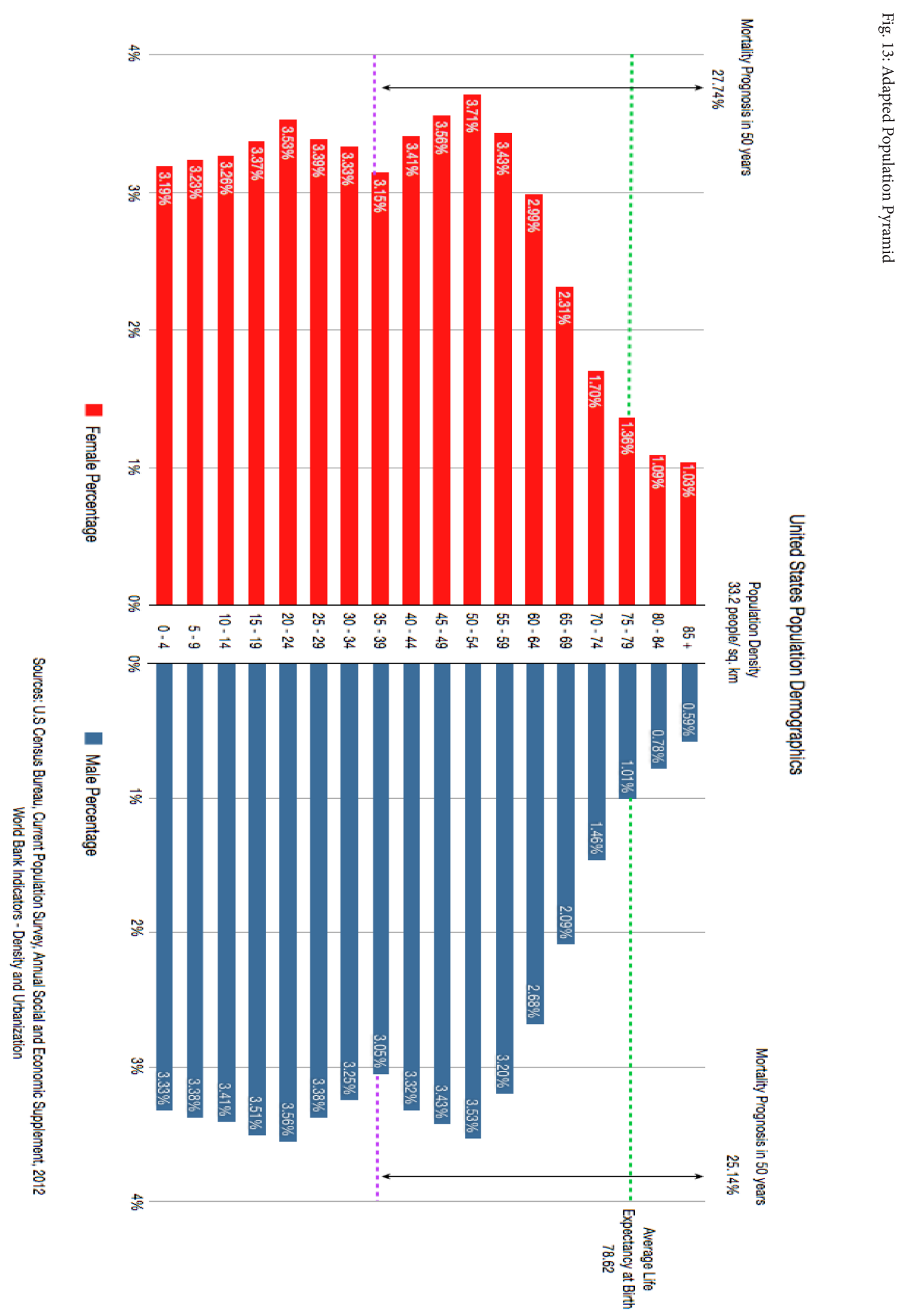


Through this depiction, we can predict what proportion of the population will have died in the next 50 years (in the case below, $27.74 \%$ of males and $25.14 \%$ of females). The next step which is required is to analyse the birth rates to forecast a new base of the 2040/2050/2060 population structure. By incorporating this additional information, we obtain a much larger overview of current and future scenarios.

Whilst the proposed amendments shed more light to the importance of demographics, further changes can be made to highlight specific economic variables. These have been omitted in the diagram above to avoid excessive complexity, but are explained here.

- If an in depth look at pension funds is required, a horizontal average retirement age can be added. In effect, it will ascertain the percentage of the population which would be eligible for pension entitlements against the percentage of people who are currently employed in the workforce.

- Supposing a country wishes to research net migration levels, the horizontal bars representing age groups could be broken down by country of origin or ethnicity. This could be especially useful when comparing the effects of net migration on jobs and unemployment, social security, pension contributions, housing prices, consumer demand etc.

- Additionally, an area which is often discussed but rarely analysed is the increase in reproductive ages through medicine and certain medical procedures. Therefore when we contemplate the next generation and incorporate birth rates, we can assess the proportion of the population (through the area in the population structure) which are able to procreate. Naturally, if this area widens (i.e. people can have children at later ages), how will this affect our future population structure?

- Similar to the previous point, we observe two factors working against one another to determine birth rates: namely the Demographic - Economic paradox and the ability to have children at older ages. The Demographic - Economic paradox states that as a country becomes more developed and prosperous, the birth rate falls. This is the main reason for the United Nations forecast of a global population levelling out at around 11 billion people, and, although debatable (as mentioned before in the critique), it is occurring in Japan. In- deed, the population forecast of Japan is expected to decline within the next few generations to just under 90 million people.

These hypotheses have touched upon the transition from demographic structures to economic variables, which will be explored in chapter 3 . The subsequent chapter will statistically explore the correlations between growing populations with the prime economic variables. Furthermore, they will provide evidence to expound the questions 5, 6 and 7 mentioned above, and draw conclusions regarding the expectations of our future economy given the expected assumption of continued population growth.

\section{The Merger of Demographics with Macro Economic Facets}

This paper will now turn its attention away from the scenarios and predictions of demographics and concentrate on its links with economic variables. The last bullet point above allows for a smooth transition from exclusively concentrating on demography to the basic relationships between population structures and economic development. There are, however, many unmentioned aspects which perhaps oversimplify the conclusion of the Demographic - Economic paradox.

a) Does population size affect economic development?

b) Does economic development affect population size?

c) Is/Are there one or many external variables which have an effect on both?

Considering Japan as an example - the cost of living is reasonably high and the land available is particularly scarce. Japan has been locked in a period of economic stagnation for many years and has some cultural traits toward collectivism as opposed to individualism. ${ }^{30}$ Its population growth and economic development have therefore been impeded by its current population size reaching a density maximum. The fact that Japan seems to be the fastest population in decline and one with stubbornly stagnant economic development may be explicitly due to the restriction on available land for development. A generalised

30 The Hofstede Center, http://geert-hofstede.com/japan.html 
Fig. 14: Interrelationship between Economic Development and Population Size, including mutual influences

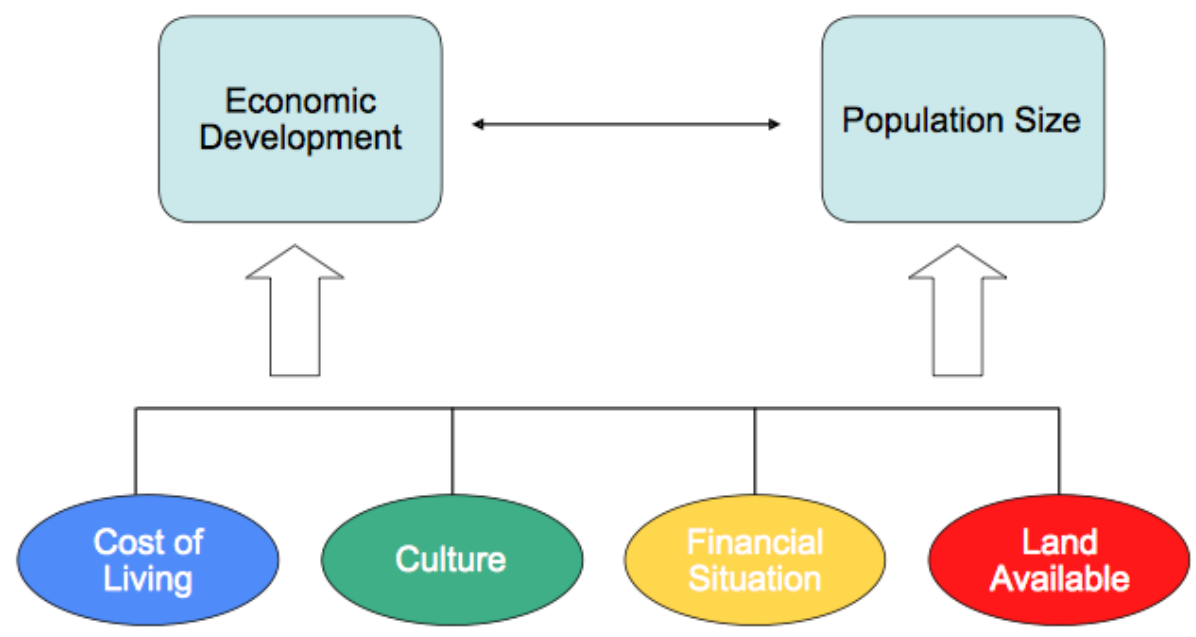

overview of the interrelationship between economic development and population size, including sub-variables, has been included figure 14 .

A generalised overview of the interrelationship between economic development and population size, including sub-variables, has been included figure 14 .

A more generalised response to the 3 questions posed above is presented by the author below.

Regarding a), population size definitively affects economic development, in fact it is a prerequisite of it. The larger the population, the larger the potential productive capacity of a country, so there is a noticeable positive correlation. The statistical relationship between the two is quantified in the next chapter.

Considering b), in some capacity it can be observed that economic development affects population size, both positively and negatively. The more economically developed a country is (and assuming the wealth is distributed at least partially to the local population), the more people are able to afford the health care and other resources, reducing child and mother mortality rates. The corollary of this argument is the demographic - economic paradox which states that birth rates will fall as economic development increases, due to improvements in education and the ability to accrue greater wealth. In this sense, people will "put off" having children until later, thus reducing the number of children they can have during their lives.

Concerning c), it is the authors' firm belief that mixtures of the 4 variables mentioned in the diagram above have a profound influence on both economic development and population size. In particular, the size of land available provides additional resources in the form of raw materials, as well as space for the development of housing, infrastructure and manufacturing. These in turn provide the goods and services which increase economic development.

Before the statistical analysis commences, the author would like to draw upon his previous publication of financial crisis forecasting and recall the following equation hypothesised:

Fig. 15: Scarcity Problem Breakdown ${ }^{31}$

Finite Supply

Total Demand for Necessities
Gross Domestic Product

Price of Basket of Goods for One Person *Number of People in Population

31 Chrisopher North, 2013, Financial Crisis Forecasting: Causes, Effects and Systemic Factors Influencing Financial Crises, page 123. http://othes.univie.ac.at/27974/1/2013-04-30_0610700.pdf 
We can see the basic economic problem described on the left hand side of the equation; a finite supply of resources divided between infinite wants and needs. As population size increases, demand and the population strain on resources rises. Economic development is often symbolised by GDP growth, which is also included in the equation. This being the case, the influence of population size and growth on economic variables is unavoidable.

\subsection{Government Budget Constraints of Gro- wing Populations}

This subsection aims to ascertain a common link between population growth and the burden on the government in the form of budget expenditure. In order to properly examine this trend, the budget expenditures of the category termed by the White House as 'human resources' are considered. These include social security, income security, medicare, war veteran and education outlays.

The assertion that population growth exacerbates economic problems has been postulated by this paper with several avenues of deliberation and theory. The following analysis wishes to highlight the changes in government expenditure over the last half century, especially those expenses which population growth plays a role in. Firstly, America has often contemplated a future pension crisis caused by underfunded pension funds. Naturally, the more people there are, the greater the strain on pension funds in nominal terms. Likewise, the same logic applies when considering unemployment. Therefore as population levels rise, we can expect some form of correlation through an increased allocation of the budget towards social and income security expenditures.

The most common rhetoric between democrats and republicans is the excesses in defence spending. However, upon investigation it is noticeable that defence has declined remarkably as a percentage of the overall budget allocation over the last 50 years. Previously, defence expenditure accounted for roughly $60 \%$ of the overall budget. By comparison, 2017 forecasts predict this figure to be $13.9 \%$. So what expenditures are increasing to offset the proportional reduction in defence spending?

In fact, $70.4 \%$ of today's budget is set aside for 'human resources', of which income security and social security account for the largest proportions. The

Fig. 16: United States Historical Budget Expenditure as \% of Total Budget ${ }^{32}$

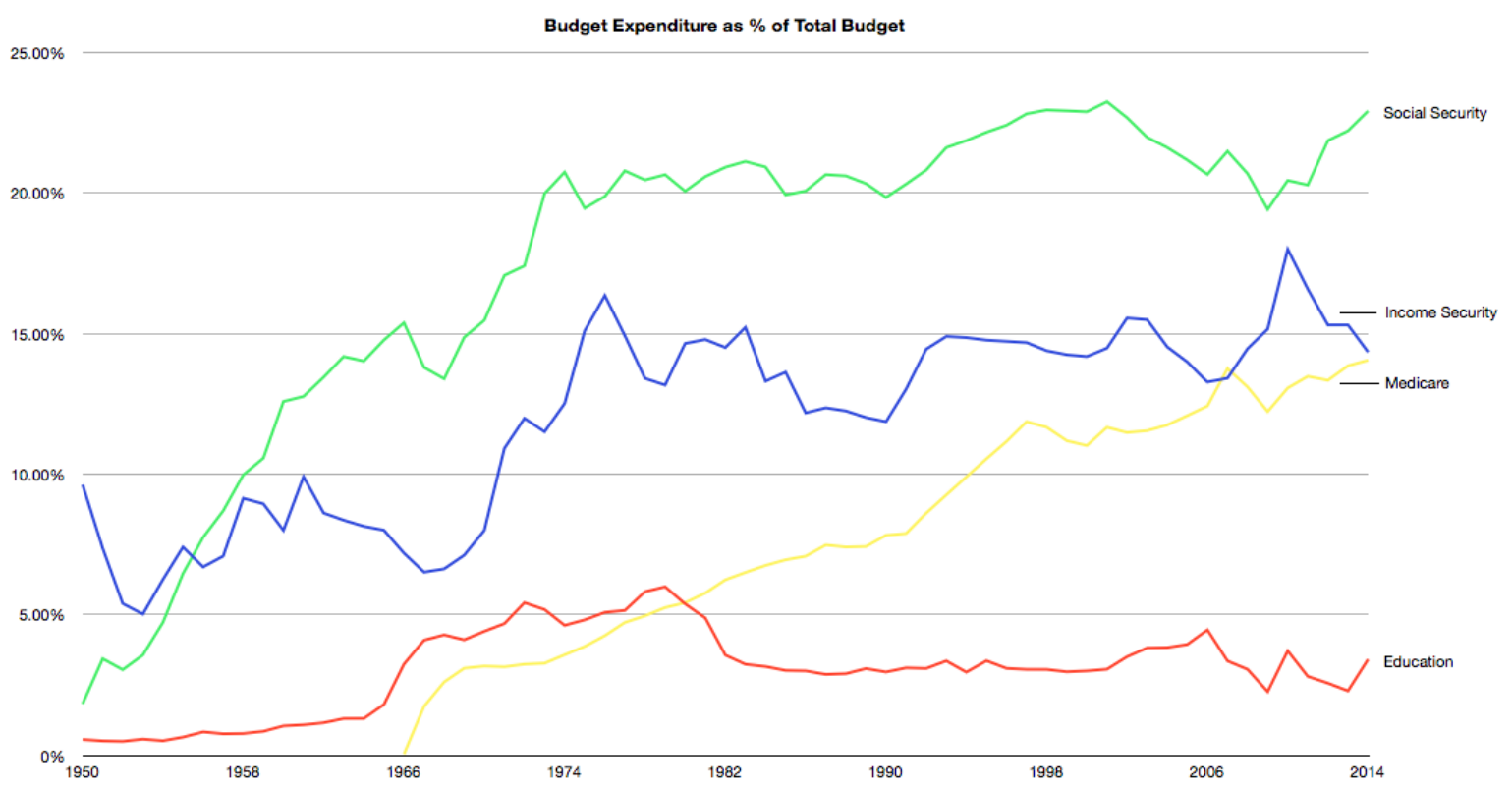

32 With House Office of Budget and Management - Fiscal year 2014 Historical Tables, pg. 27-70. http://www.gpo.gov/ fdsys/pkg/BUDGET-2014-TAB/pdf/BUDGET-2014-TAB. pdf 
trend of how expenditures have developed over time are displayed in figure 16.

There are several interesting conclusions which can be drawn from this chart. The most prominent trend is that medicare, income security and social security have all been allocated a greater portion of the total budget over time. Of these, income security's share has increased by half (from roughly $10 \%$ to $15 \%$ ), whilst social security expenditures relative to the total budget percentage have increased over five-fold. Medicare, which was only introduced in 1966 , is now assigned approximately $15 \%$ of the budget, and has grown at significant pace.

Despite this, there are continuous concerns portrayed by both the media and parliament regarding deficits in pension funds, unemployment benefits and the quality of healthcare in America. By contrast, it is also worth mentioning that expenditure on education has remained at a steady proportion of the total budget over time. It would appear that a trend is developing over time, such that the category of human resources are being split into necessity and luxury expenditures. Necessary expenditures are those which the public has the highest demand for, i.e. a certain level of health care, unemployment benefits to cover the basic cost of living, veterans benefits and state pensions. Without any of these expenditures, the poverty rate and health of the population would deteriorate - and the problem is that these expenditures are continuing to rise. Correspondingly, although high levels of expenditure on education are desirable, it is unfortunately not an absolute necessity good, and the majority of proportional budget increases have been allocated to more pressing needs. Population levels are incorporated into this through a simple correlation between the number of people and the proportion of the budget allocated to human resources.

Upon closer inspection, the correlation between the two variable in the table above is 0.95 , a very high indicator that a growing number of people directly influences the growth of human resource outlays, and puts an added strain onto the overall budget. To accommodate such increasing needs, optional/luxury expenditures are foregone or have remained at stagnant proportions, which include education, energy expenditures, natural resource and the environment outlays, community and regional development costs and science funding.

In terms of a future prognosis, the White House Office of Management and Budget have forecasted increasing expenditures in Human resources together

Fig. 17: U.S Human Resource Expenditure and Population Growth ${ }^{33}$

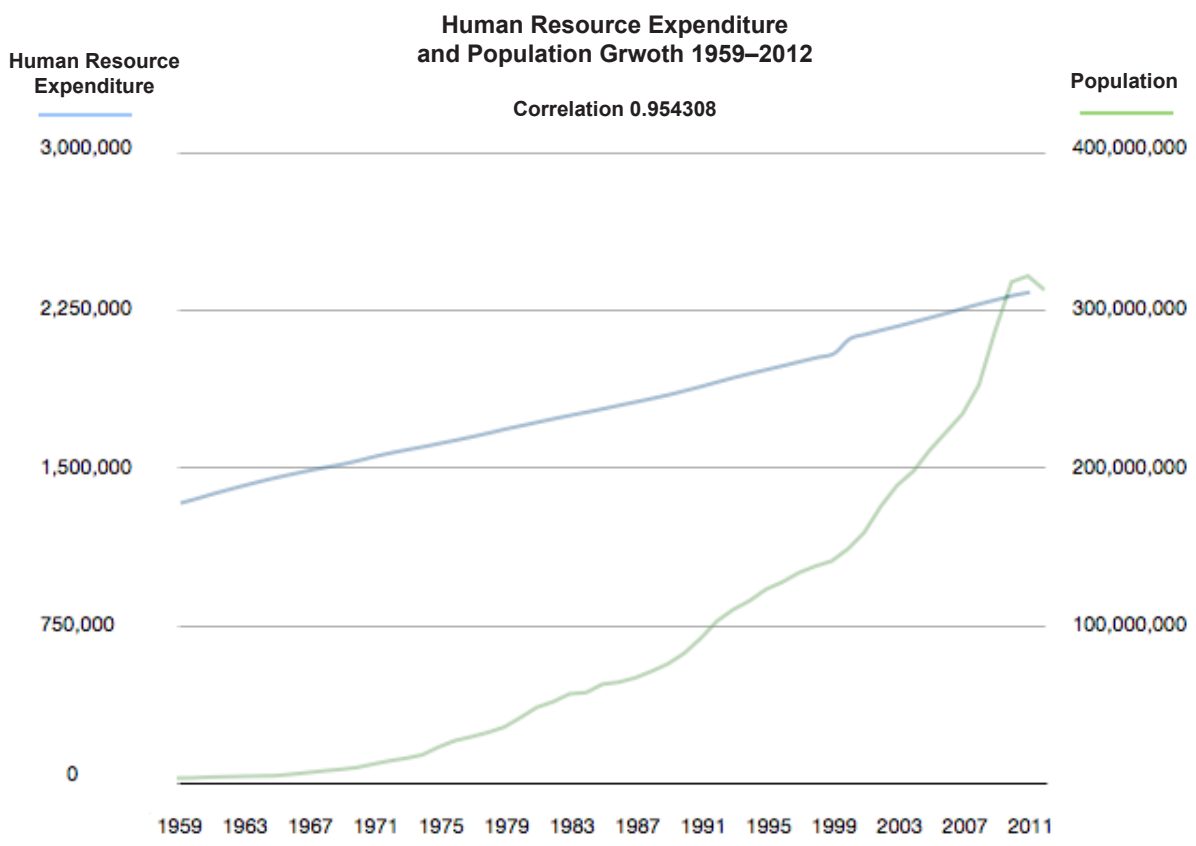

33 With House Office of Budget and Management - Fiscal year 2014 Historical Tables, pg. 27-70. http://www.gpo.gov/ fdsys/pkg/BUDGET-2014-TAB/pdf/BUDGET-2014-TAB. pdf 
(Figure 17) and a reduction in defence spending which is offset by increases in Interest expenditures. Outlays into the so-called luxury expenditures remain steady, however the underlying concept is the need for social security and income security reform to free up the capital required for education and science projects.

Social security costs are increasing due to labour excesses in unskilled markets and a lack of highly skilled individuals for specialised jobs. In such markets, mechanisation will continue to obsolete service sector jobs as they become automated, raising the number of people requiring unemployment benefits. In addition, as populations grow and retirement ages rise, so does the number of people in the workforce. In effect, supply of labour is increasing and demand is subdued. As a result, the forecast of increasing expenditures in 'human resources' is perfectly understandable.

The implications of this are quite worrying. A significant reform of human resource costs in required without reducing contributions to the most vulnerable in society. One of these reforms is the increase in retirement ages, which lowers the number of people who are entitled to pension support, thus reducing costs. Additionally, individuals earning above a certain income bracket (e.g. \$65.000) per year after retirement could be made exempt from state pension contributions, which focusses pension payments towards those in greater need. Taxes could also rise to allow the budget to increase spending in other needed areas, however this would not avoid the rise of human resource costs.

If such reforms do not occur, the bottom line is that long term human resource costs are driving governments towards bankruptcy. As seen in Greece, government bankruptcy causes bond ratings to drop, interest rates to rise and liquidity issues to occur. The extreme alternative of reducing such pension and unemployment contributions for the sake of government solvency is also detrimental to the welfare of society, as poverty levels will rise significantly. These long term implications necessitate reform or redevelopment in the structure of our human resource expenditure today.

\section{Statistical Analysis of Population Corre- lations}

The majority of the discussions and working papers regarding the effects of population growth tend to be those of assumptions and theory without statistical findings. It is often the case that social parameters, rather than economic ones, are discussed within this context. This paper therefore attempts to offer its own hypotheses and use both theory and correlation coefficients to provide a basis for its arguments.

The first issue is to narrow the geographical area to a certain degree, so that a high number of reliable observations exist. In essence, there is no value in analysing the effect of population growth on GDP in a middle eastern country (e.g. Iraq) between 2000 2013, as the external shock of war has severely impacted both population size and economic growth. Nor can single european countries be analysed on a case by case basis, as their inclusion into the European Union has changed the course of population size (through net immigration) and economic growth (through the entry into a new european market with access to large investments). As a result, the most prudent action would be to use the United States for the purpose of this analysis, which has had no large population shocks or external economic shocks. In addition, the economic and population data has been accurately recorded since 1960 by government institutions. This provides a large enough sample to observe the long term correlations.

To emphasise the fallacy of equating observations made in America against those in Germany and Italy, we first have to look at the structure of the European Union. The free movement of goods, services and labour in a market with a single currency simply cannot be compared to one which is completely autonomous. Furthermore, the value of the Euro is an average, such that it is undervalued for the more developed countries and overvalued for weaker economies. Naturally, this has an extreme impact on the balance of payments for all participating countries. Furthermore, despite the fact that the EU increases trade within its borders, restrictions exist which may hinder foreign goods and services entering european markets. Since Greece's inception into the European Union, German imports to Greece have risen sharply whilst exports remained constant. This imbalance is one of the major reasons for Greece's bankruptcy. 
In terms of national debt within the European Union, both domestic and european bonds markets exist currently, although the latter is starting to dominate and the setup is increasingly acting like a single market. Following the financial crisis of 2008 and the sovereign debt crisis which followed, the IMF and european countries agreed to bail out Greece from its immediate debt obligations, which demonstrates the unity in european bond markets.

Given the presumption that growing populations increase the strain on the planet's finite resources, the effects should be observable in economic indicators. One of the most obvious of these is through the price of consumer goods. The more people there are, the higher the demand for goods and services produced (demand-push inflation). However, the evident increase in prices is not solely due to population growth, consequently external factors may contribute to draw false conclusions.

Likewise, money supply growth is in turn a response to a number of external factors, such as regulation, interest rates and the monetary base. It is the monetary base which is the most important of these, which represents the asset side of commercial banks balance sheets. By comparison, the money supply increase would be denoted by the liabilities side of the balance sheets.

\subsection{Monetary Base Analysis and the Inequality of Wealth}

To clarify the introduction to this chapter, it is the authors recommendation to analyse the relationship between the monetary base and population growth, as this will circumvent the influence of external variables on the money supply.

Anticipating a positive linear relationship between these two variables, the first hypothesis states that as population levels increase, the monetary base will also rise. The raw figures were obtained from the Federal Reserve Bank of St. Louis (Adjusted Monetary Base) and the United States Census Bureau (Department of Commerce) and accounted for 54 yearly observations between 1959 and 2012. This and all other tables will be included at the end of this paper.

\section{Correlation yielded between United States Monetary Base and Population: 0.79875}

This result demonstrates a high positive correlation between the monetary base of America and its population. Nevertheless, it is important to examine existing economic theory regarding the quantity of money and interpret it in the current economic climate in light of this result.

With regard to economic theory, there are 2 contrasting quantity of money theories. Milton Friedman posited a direct relationship between increases in the supply of money and price inflation. Obviously, the events in 2008 proved that this theory could not be directly applied in a practical sense (2008 reported a $25 \%$ increase in the money supply and only $0.1 \%$ inflation). The counterargument came from Keynes, who focusses on use of money in the market. He explains that a proportion of income is not used for transactions, it is either saved or invested. Changes in output should still be realised under this notion.

Our current economic climate (post 2008) demonstrates that despite significant monetary expansion, inflation has remained at relatively low levels. This is in part due to the changes in regulations post 2008 which require banks to hold a larger proportion of deposits as cash. Notwithstanding this, we are also noticing stubborn levels of unemployment and disproportionally slower increases in output than would be expected under Keynes' assertions. The author would therefore like to highlight another significant variable which has undoubtedly had an effect on the quantity theory of money; the distribution of income growth since 2008 .

So who are the recipients of money supply increases, and more importantly the wealth created by monetary expansion policies? In 2012, Emmanel Saez, professor at the University of Berkeley, released a document titled 'Striking it Richer: The evolution of Top Incomes in the United States'. He states that "top $1 \%$ incomes grew by $31.4 \%$, while bottom $99 \%$ incomes grew only by $0.4 \%$ from 2009 to 2012". ${ }^{34}$ However, his report suggest that this accumulation of such vast amounts of wealth is a relatively new concept:

"The labour market has been creating much more inequality over the last 30 years, with the very top

34 Emmanuel Saez, "Striking it Richer: The Evolution of Top Incomes in the United States". UC Berkeley, September 3, 2013. 
earners capturing a large fraction of macroeconomic productivity gains." 35

This report went viral in 2013, and questions concerning inequality were posed to President Obama a week after its publication. The president replied that globalisation and technology were obsoleting jobs on the lower end of the spectrum, thereby concentrating wealth at the very top. This can serve to inflate bubbles and threaten the economy. ${ }^{36}$

Business Insider also commented on this issue, citing the problems of job creation and a "slack labour market that holds down wages and also deprives businesses of the customer base that they need to invest and grow $^{137}$

These sources point to inequality as the cause of the disconnect between the money supply, inflation, job creation and real wages. They would also seem to support the author's hypothesis that the Keynesian notion of money demand doesn't apply when there is such a disparity in wealth creation recipients. Whilst there is room to believe that excessive money creation may lead to the hoarding of wealth by individuals, at extreme levels it may simply be impossible for so few individuals to spend such a large amount of money.

When we consider this point from a corporations point of view, it could be the case that there are not enough positive net present value projects available to invest in. The hoarding of cash may not just be on an individual basis, as described in a Wall Street Journal article which confirmed that United States companies were sitting on $\$ 1.93$ trillion in cash and other liquid assets. ${ }^{38}$

In addition, the current state of the economy would seem to suggest a mix of the two previous paragraphs.

35 Emmanuel Saez, "Striking it Richer: The Evolution of Top Incomes in the United States". UC Berkeley, September 3, 2013.

$36 \mathrm{CNN}$ Money, Obama admits $95 \%$ of income gains gone to top 1\%, http://money.cnn.com/2013/09/15/news/economy/ income-inequality-obama/

37 Josh Barro, "Here's What That Really Means". Business Insider, 95\% of Income Gains Since 2009 Went To The Top 1\%, http://www.businessinsider.com/95-of-incomegains-since-2009-went-to-the-top-1-heres-what-that-reallymeans-2013-9

38 Justin Lahart, "Companies Cling to Cash". Wall Street Journal, 10/12/2010. http://www.businessinsider.com/95of-income-gains-since-2009-went-to-the-top-1-hereswhat-that-really-means-2013-9
The majority of new wealth is concentrated heavily among a few individuals and companies, all of whom are showing a reluctance to invest. Therefore, wealth inequality is having a profound effect on economic growth and inflation.

\subsection{Money Base, Money Supply and Wealth Accrual}

The next and slightly more complex objective is to analyse the ratio between the money base and the money supply. To understand the reasoning why this is important, we will remind ourselves of the scenario set out by North (2013) under the title 'Effects of Population Growth'. ${ }^{39}$

The scenario is set out supposing a country with the population of 100 million people which is growing at a rate of $1 \%$ p.a. For the sake of simplicity, we assume that the money supply and economic growth are also increasing at the same rate, and that wealth is uniformly distributed throughout the population.

The assumption regarding a set economic growth satisfies the counterargument to the more traditional quantity theory of money (i.e. that increases in money supply will have a direct impact on inflation).

The idea behind this logic is that as economic growth increases through rising production and GDP, prices will fall as marginal variable costs drop. This is true in the purest sense, however we see in markets today that prices are not so easily adaptive (sticky prices, collusion, monopolistic power).

Returning to our scenario, and including a uniform distribution of wealth with no hoarding, inflation should theoretically be 0 . As the population increases in size, so too must the money base, otherwise depreciation would occur. Moreover, an increase in population would add to the GDP of a country and raise the demand for goods and services, adding an inflationary pressure. This is where the ambiguity between the monetary base and the money supply needs to be clarified, including the effect of monetary expansion on inflation. To recap, figure 18 demonstrates the interrelationship between population size, the money supply, economic growth and inflation.

39 North 2013 - Financial Crisis Forecasting: Causes, Effects and Systemic Factors Influencing Financial Crises, page 124. http://othes.univie.ac.at/27974/1/2013-04-30_0610700.pdf 
Fig. 18: Interrelationship between Population, Monetary Base, Money Supply, Economic Growth and Inflation (including the quantity theory of money and its counterargument)

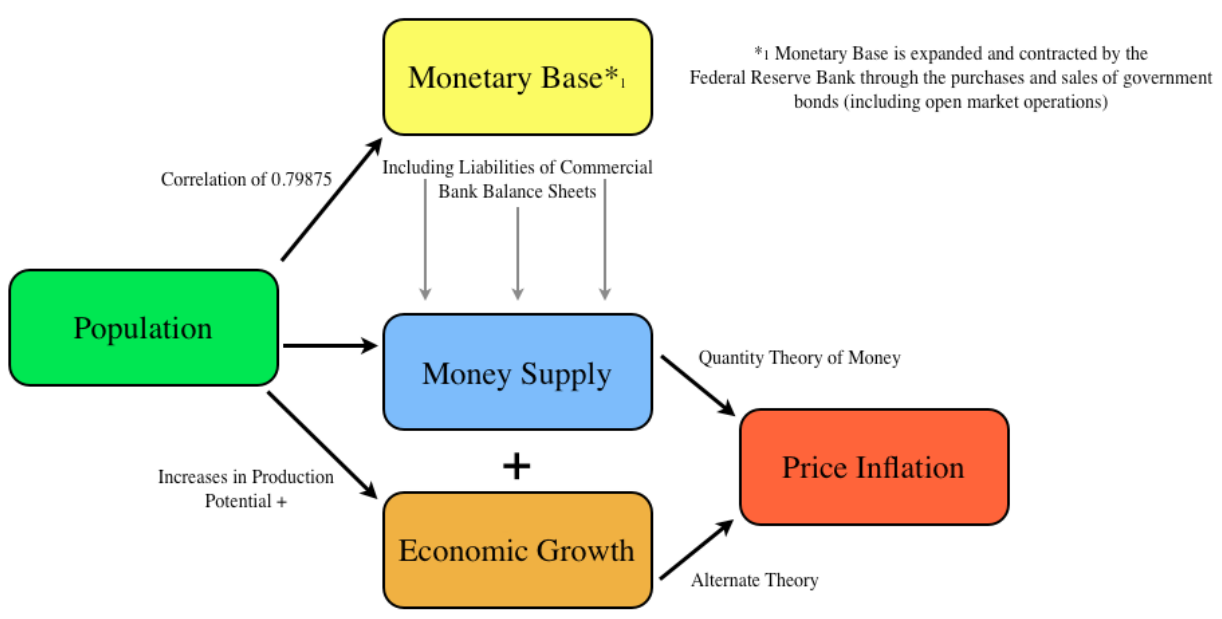

Following this diagram we can see the disjoint and misalignment of population and price inflation through the money supply. Since population levels and the monetary base have a strong positive corre- lation, the difference between the monetary base and the money supply needs further examination, and can be clarified through the standard money multiplier model. This model states the following: ${ }^{40}$

Fig. 19: Money Base to Money Supply Equation

\title{
Money Base to Money Supply
}

Monetary Base $=\mathrm{M} 0=$ Currency held by economic agents $(\mathrm{C})+$ Reserves Deposited in Commercial Banks (R)
Money Supply = M1 = Currency held by Economic Agents (E) + Money kept as Demand Deposits (D)

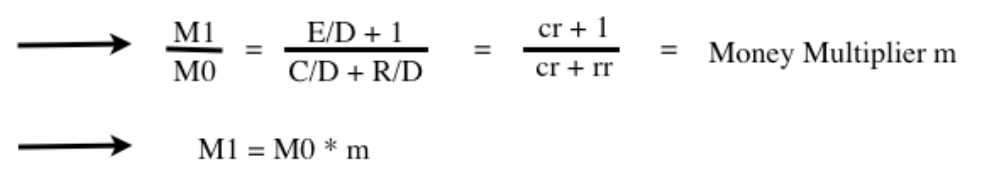

40 András Komáromi, "The effect of the Monetary Base on Money Supply". 
As a result, the money supply is greater than the monetary base by a factor of ' $m$ ' (approximately). Nevertheless this still yields several interesting conclusions:

i) The more people there are, the larger the monetary base, and therefore the larger the money supply. Assuming $\mathrm{m}>1$, the money supply is rising disproportionally faster than the increase in population, causing higher inflation than necessary. When examining the most current figures released by the Federal Exchange in America, the monetary base for $25^{\text {th }}$ December, 2013 was $\$ 3.670 .209$ billion $^{41}$, compared with the money supply (M2) figure of $\$ 11000.6$ billion $^{42}$. To clarify, M2 is described in the same text as "M1 plus savings deposits, small denomination time deposits and balances in retail money market mutual funds", which displays how the money supply is almost triple that of the monetary base, even in a time when banks are severely restricting the number of loans which would normally enlarge the money supply further. ${ }^{43}$

ii) Larger populations also are positively correlated with GDP (analysed later in this chapter), which should have a dampening effect on rate of inflation (according to the alternative theory above). However, inflation is still rising at a faster rate than population growth.

iii)Through the system of Federal Reserve government bond purchases, the monetary base is increased, which is then deposited into commercial banks and expanded via the fractal reserve system. As written in Modern Money Mechanics, a publication by the Federal Reserve, the fractal system is justified as follows:

"Of course, they (banks) do not really pay out loans from the money they receive as deposits. If they did this, no additional money would be created. What they do when they make loans is to accept promissory notes (loan contracts) in exchange for credits (money) to the borrowers' transaction accounts."44

41 Federal Reserve Monetary Base, http://research.stlouisfed. org/fred2/data/BASE.txt

42 Federal Reserve M2, http://research.stlouisfed.org/fred2/ data/M2.txt

43 Bloomberg Website, http://www.bloomberg.com/ news/2013-05-10/credit-pinch-for-small-business-impedesu-s-job-growth.html
The correlation between the monetary base and population growth for the United States is proven as 0.79875 , therefore as the population continues to rise, more government bonds are purchased by the Federal Reserve, adding to the existing national debt. This is a severe problem, as there is now a direct link between growing populations and the debt of their countries. As a result, the debt and inflation levels in a country are partially predetermined by the growth of the population through increases in the money supply.

iv) Now if the assumption of equally dividing the money supply throughout the population is relaxed, and we consider a wide distribution of wealth, then the problems mentioned in point 3) become far more serious. If increases in population exert a twofold inflationary pressure on prices, (firstly through the money supply and secondly through demand for goods and services) the effect will be increased stratification of the wealth in a country. Indeed, this is what we see in America today. where the top $1 \%$ of the population own $38 \%$ of the wealth and the bottom $60 \%$ own just $2.3 \%$. ${ }^{45}$ Furthermore, the Washington Post displayed that poor individuals are becoming increasingly poorer, whilst the richest members continue to accrue the majority of created wealth. ${ }^{46}$

To certify this claim, the statistical measurement of wealth equality known as the GINI coefficient is particularly useful. It ranks between 0 and 1 , which represents the range from a uniform distribution of wealth to a completely unequal one respectively. In November 2013, the Economist posted an article using this method and concluded that America is the most unequal country in the world. ${ }^{47}$ Janet Gornick, director of a CUNY research centre on inequality in nations, mentioned that "it's not just the size of the social-policy system that matters; the way that

45 Senator Bernie Sanders, http://www.theguardian.com/ commentisfree/2013/jun/02/us-economy-recovery-wealthinequality

46 The Washington Post, http://www.washingtonpost.com/ blogs/wonkblog/wp/2013/03/06/this-viral-video-is-rightwe-need-to-worry-about-wealth-inequality/

47 The Economist, "Gini in the bottle", November 26, 2013 http://www.economist.com/blogs/democracyinamerica/2013/11/inequality-america 
Fig. 20: American Wealth Accrual 1983-2010 (Source: Wolf 2012, Economic Policy Institute)

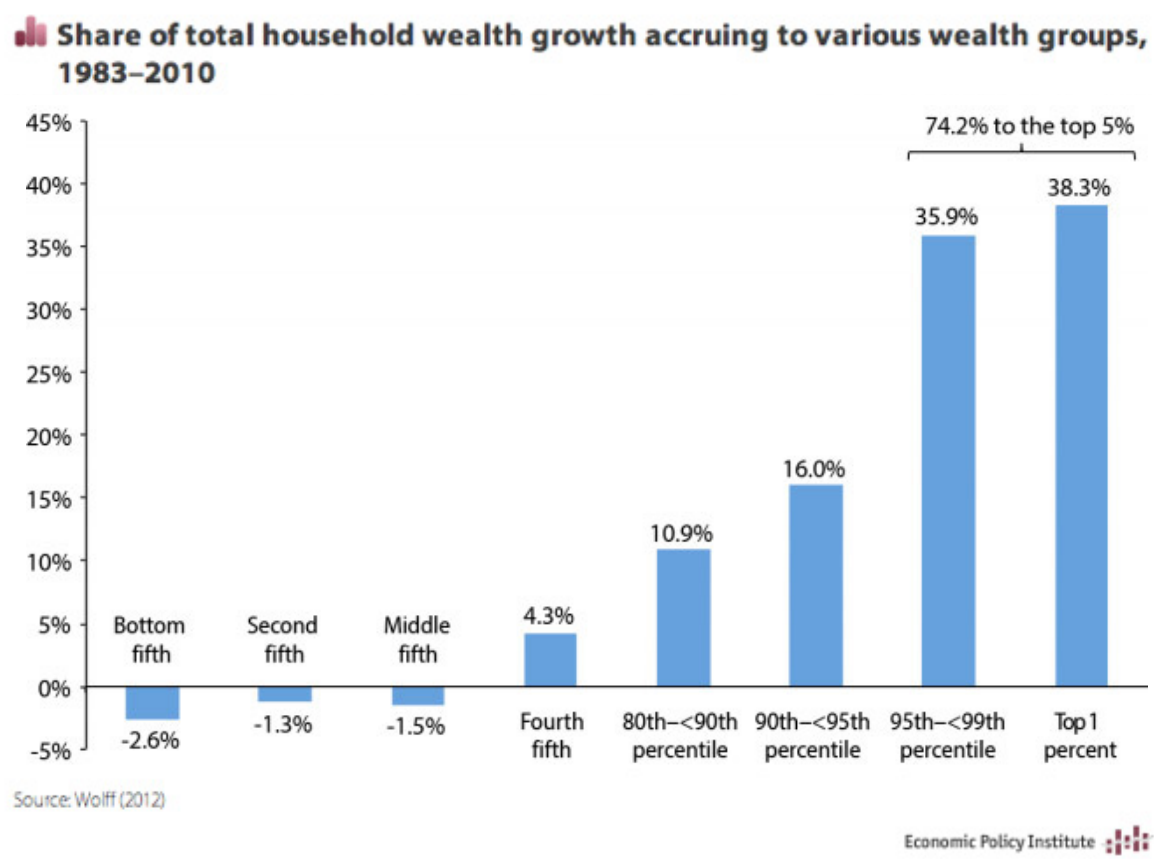

it's structured also matters". ${ }^{48}$ The disproportionately excessive increases in the money supply in relation to population growth is watering down the wealth of the working and middle class via inflation, benefitting only a handful of wealthy individuals at the top end and widening the wealth spectrum. ${ }^{49}$ The link here is evident; population rises which influence levels of the monetary base (and therefore the money supply) can cause inequality to rise.

So is this increase in wealth inequality confined to just America, or is this a worldwide pandemic? Oxfam produced an analysis on a 2013 Credit Suisse Global Wealth Report, showing that the richest 85 people in the world are now worth more than the poorest 3.5 billion. In effect, less than 100 people have more wealth than half of the human population, which shows profound inequality across the world. ${ }^{50}$ The richest individuals come from a variety

48 Luxembourg Income Study, "Inequality - it Matters". http:// lisdatacenter.org/wp-content/uploads/janet-bio/gornickfolio-2013.pdf

49 United Nations, 1999, Human Development Reports. http:// hdr.undp.org/en/reports/global/1999/en

50 Washington Post, "10 Startling facts about global wealth inequality". http://www.washingtonpost.com/blogs/wonkblog/wp/2014/01/22/10-startling-facts-about-global-wealthinequality/ of backgrounds, however the trend still applies that the more people there are, the more unequal the distribution of wealth.

\subsection{GDP, Inflation and Debt Correlations to Population Growth}

Now that it has been ascertained that wealth inequality is on the rise, the flaw of measuring a country's prosperity through GDP increases is apparent. Whilst GDP rises may be due to mechanisation, a workforce is still required to efficiently manage machines and raise output wherever possible. An unequal distribution of wealth could hinder GDP growth, as hoarding may prevent investment into projects which would expand the economy. Naturally, as pointed out by Ray Kurzweil in his book 'The Singularity is Near', technological progress is rising at an almost exponential manner, which gives rise to increasing levels of output. Therefore, the effects of population growth with regard to GDP should be interesting.

\section{United States Population Growth to GDP Growth Correlation: 0.9778}

For the purpose of this analysis, the website USgovernmentspending.com provided the information 
of nominal GDP in America from 1959-2010, including a large number of sound observations which encompass several economic, social and political changes within the country.

When making reference to economic growth, we can observe an extremely strong correlation between population figures and GDP in the United States. In the future, the author predicts a detachment from this orm, as population growth will have to submit to environmental constraints whilst productive capacity continues to rise unabated. As a result, the analysis of this particular timeline is optimal, as future technology is becoming less labour intensive and is producing goods at accelerated rates. An example of this is a modern factory, some of which are now predominantly automated with few workers. Comparing this with 50 years ago shows the profound change in the employment of our labour force, and in today's modern society the service sector (in which over $80 \%$ of the American workforce is employed) is also showing signs of obsolescence due to automation. Classic examples of this can be demonstrated through the modernisation of retail shopping, where supermarkets have automated checkout services and online shopping has undercut high street prices, forcing companies to close. The trading floors in Wall Street and national stock exchanges used to be crowded with people: now those jobs have been made obsolete by computers.

To provide a comparison, a similar examination of Germany's population-GDP correlation between 1970 and 2012 was undertaken. In this case, the correlation was 0.86 , which still signifies a strong relationship. ${ }^{51,52}$ Nevertheless, it is important to notice that the population of Germany has decreased since the turn of the century. This would give credence to the alternative theory i.e. the emergence of a detachment between the 2 variables through mechanisation (which caused rises in GDP as well as population growth) and diminishing populations in developed countries.

51 Statistisches Bundesamt Deuschland, Population Data. https://www.destatis.de/DE/Startseite. html?nsc=true\&https $=1$

52 OECD, GDP Data. http://stats.oecd.org/Index. aspx?datasetcode $=$ SNA_TABLE1\#

\section{United States Population Growth to Average Yearly Inflation Correlation: $\mathbf{- 0 . 1 5 1 5 7}$}

In particular, this result detaches the notion of a relationship between population growth and inflation, and even suggests a small negative correlation between the two. Nevertheless, this outcome is surprising, especially given the high correlations between population growth and the money supply/GDP. The conclusion that can be drawn here is that inflation has become more detached from changes in the money supply than previously thought. A possible rationale for this could be the increased use of money as a store of value rather than as a facilitator of transactions. Price setting may also be independent of demand and supply within an economy, explaining this low negative correlation.

If we follow the hypothesis that population growth raises both the demand and supply sides for goods and services (increasing GDP in the process), prices should theoretically be reacting to this. Instead, it can be suggested that prices are set with the view of generating a given level of revenue, and should only be altered if either targets are not achieved or if profits can be increased through further price alterations. This would explain the disconnect between the money supply and inflation correlations with population levels.

\section{United States Debt - Population Correlation: 0.92222}

Similar to the first two correlations, we can remark that there is a significant interrelationship between population size and debt levels. The rationale behind this finding is relatively clear: all governments wish to achieve a continuous low level of inflation, which symbolises growing prosperity and production. As populations rise, the monetary base is expanded to avert an appreciation of the currency (and deflationary pressure), and disseminated and deposited into commercial banks. The procurement of the additional monetary base comes at the cost of the sale of government bonds to the Federal Exchange i.e as populations rise, so too does debt. It is a somewhat debilitating supposition that as the number of people in a country rises, debt levels also increase. Yet this does seem to be the case and is an inherent inconvenience to growing populations, especially as we can see in point i) that wealth inequality is also broadening everywhere. Whilst the United States provides 
the most classical and obvious case of a population to debt correlation, the UK public sector net debt also demonstrates a continual and steady rise over the past decade, which is predicted to continue at least until 2019. ${ }^{33}$ Consequently, similar correlations are expected for the UK.

\section{Current Account Position to Population Correlation: - $\mathbf{0 . 8 5 3 5}$}

Correlating these two variables may seem slightly obscure, however the product of the statistical analysis was quite shocking. The analysis suggests a highly negative correlation between population growth and the balance of the current account, i.e. the more people there are in a country, the worse the country's current account position. The author will lay out his reasoning for this correlation and explain why the United States is a particularly good example to use.

The hypothesis was that current account positions become exacerbated with higher populations. A smaller country which requires certain non-domestic raw materials (i.e. oil, agricultural products, precious metals) will import them to satisfy the demands of its citizens. In the case of America, the imports outweigh any exports to foreign countries, and therefore a balance of payments deficit accumulates. This is one of the major problems of developed countries, as they rely on the natural resources of foreign countries, having depleted their own. So what is the difference between a smaller and larger developed country? Simply the number of resources required to perpetuate the lifestyle of the citizens. Consequently, in developed countries larger populations will result in greater balance of payments deficits. Naturally, there are some exceptions to this case, for example if a developed country were able to export specialised goods and services (United Kingdom financial services, American military equipment, Japanese computer technology or German manufacturing), this would negate the cost of imports.

The German economy provides an intriguing counterargument to the author's prediction. Germany's current account has built up a surplus system over the past decade which now amounts to $6 \%$ of its GDP. Furthermore, China has also been building up its current account surplus over the last few years despite population growth. This provides evidence that

53 Richard Anderson, "UK debt and deficit: All you need to know", BBC News. http://www.bbc.co.uk/news/business-25944653 the findings in America cannot be used as a worldwide template.

Nevertheless, Germany and China are unique cases. Germany's inclusion in the European Union and use of the Euro means that it is using an undervalued currency in relation to its strong economic growth. Inflationary pressure from countries such as Italy, Spain, Greece and Ireland have allowed Germany to take great advantage of an abnormally low exchange rate with other countries for its goods and services, giving Germany a competitive edge in international markets. If Germany still had the Deutsche Mark and still grown at such a fast rate, we would have observed a strong appreciation in its currency, which would have influenced its current account. Likewise, China has been able to exploit export led growth through two means, namely depreciated wages and a quasi-fixed currency over the last decade. Although the Yuan is starting to appreciate today, the majority of this current account surplus was accumulated with an undervalued currency, and therefore population cannot be correlated with its current account surplus. The only other viable option would be to assess the current account of the United Kingdom, who have retained the pound and have a floating currency whose value is not directly dependent upon EU countries.

The Office of National Statistics recently published its 2014 current account deficit, which equates to 5.1\% of GDP (or $£ 20.7$ billion nominally). As mentioned in the Wall Street Journal, this is the widest deficit as a percentage of GDP since $1989 .{ }^{54}$ What caused this deficit to accumulate? A decline in the demand for goods and services which the United Kingdom produces, coupled with rising prices of imported goods and raw materials, has

Nevertheless, the effect of growing populations in the developed world should also be considered when discussing the nominal values of imports, especially raw materials. It is the author's prediction that as $2^{\text {nd }}$ and $3^{\text {rd }}$ world countries develop, the shortage of such raw materials will become increasingly acute, raising prices and worsening the current account of developed countries further. A growing population will only serve to fuel the demand for these finite resources.

54 Jason Douglas and Ilona Billington, "UK Balance of Payments Worsens", Wall Street Journal. http://online.wsj.com/ news/articles/SB100142405270230486690457926971281194 7376 
All of the interrelationships above provide results which can be rationalised, however they offer an insight into the role of population as an independent variable which has intrinsic and strong ties with economic parameters. The role of population size has been on the periphery of economics until now, though several population awareness groups are beginning to emerge and are expressing their desire to bring this topic to the forefront in mainstream macro economic policy. As one environmentalist put it, "is there any problem on the planet that we can think of which could be solved or improved with a greater population?" Unfortunately not.

\section{The Necessity to Quantify Environmen- tal Elements}

The current economic paradigm involves the pursuit of growth and production to continuously improve the lives and wellbeing of citizens. This is derived from the consumption of finite raw materials to provide the 'necessity' and 'luxury' goods and services required to serve our needs and wants.

As is expected, these resources are obtained from our environment, be it through mining, drilling, use of arable land for agriculture, forestry or the consump- tion of energy resources. As these resources are extracted, the marginal cost to the environment increases, and we have now arrived at the stage where the majority of readily available resources are exhausted. The environmental cost of extracting new resources is therefore significant, which is depicted in figure 21 below regarding the increase in marginal cost of resource extraction.

Until recently, the only constraint of available resource extraction has been a market one, i.e. the extraction will only occur if market prices can cover the cost of obtaining the resources in the first place. Likewise with population, we see that larger populations exert higher demands, driving up the price of such materials. This is the core idea behind a direct link between population growth and environmental degradation. All measures by governments to restrict environmental damage have been through attempts to artificially raise the cost of consuming raw materials, as opposed to quantifying the actual damage caused. In the case of pollution (caused by the consumption of oil, gas and other fossil fuels), direct taxes, cap and trade markets and regulation are all designed to discourage consumption through price adjustments. Nonetheless, the long term impact to the environment once the extraction of raw materials has taken place has not been quantified. The only

Fig. 21: Increase of Marginal Environmental Cost as Resource Extraction Increases

\section{Marginal Environmental Cost}

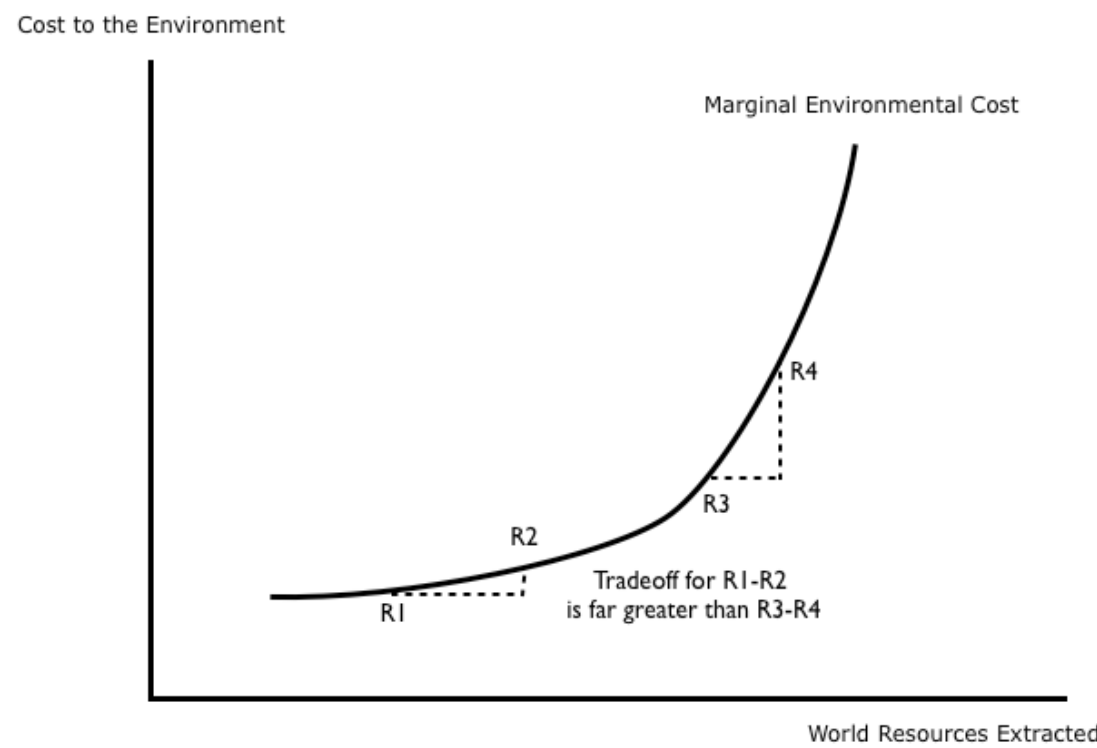


method of adequate environmental cost analysis is through a replacement cost calculation, as long term impacts are becoming increasingly apparent today. This is shown in the diagram underneath.

The cost of extraction is rising due to the extended efforts made by companies to search for and acquire new resources. In particular, oil companies spend millions of dollars on exploration, and the average cost of oil discovery has risen from $\$ 1.18$ barrel to over $\$ 3$ in $2010 .^{55}$ Equipment such as drilling platforms need to be set up, as well as transportation of the oil to its destination. As easily accessible oil is exhausted, companies are now having to drill to far deeper levels (and offshore) to maintain their quotas. One alternative to this is to extract shale gas from deep underground via a process known as hydraulic "fracking". Currently, this has caused grave concerns by all environmentalist groups, including the potential poisoning of underground aquifers with methane and other harmful gases, ${ }^{56}$ the increased likelihood of earthquakes and general harm to human health. ${ }^{57}$ The increase in extraction costs, both financial and environmental, are depicted in the table below. It is worth mentioning that the true environmental cost is difficult to quantify, and thus may be grossly understated by today's estimates (Figure 22).

\subsection{Fracking and the Need for Resources}

Documntaries such as 'Gasland' and 'The Sky is Pink' cite many sources to corroborate the claim that environmental damage is caused by fracking. It is known that regulations in this field are particularly lenient,

Fig. 22: Marginal Environmental Cost in Relation to Extraction Costs

\section{Marginal Environmental Cost in Relation to Extraction Cost}

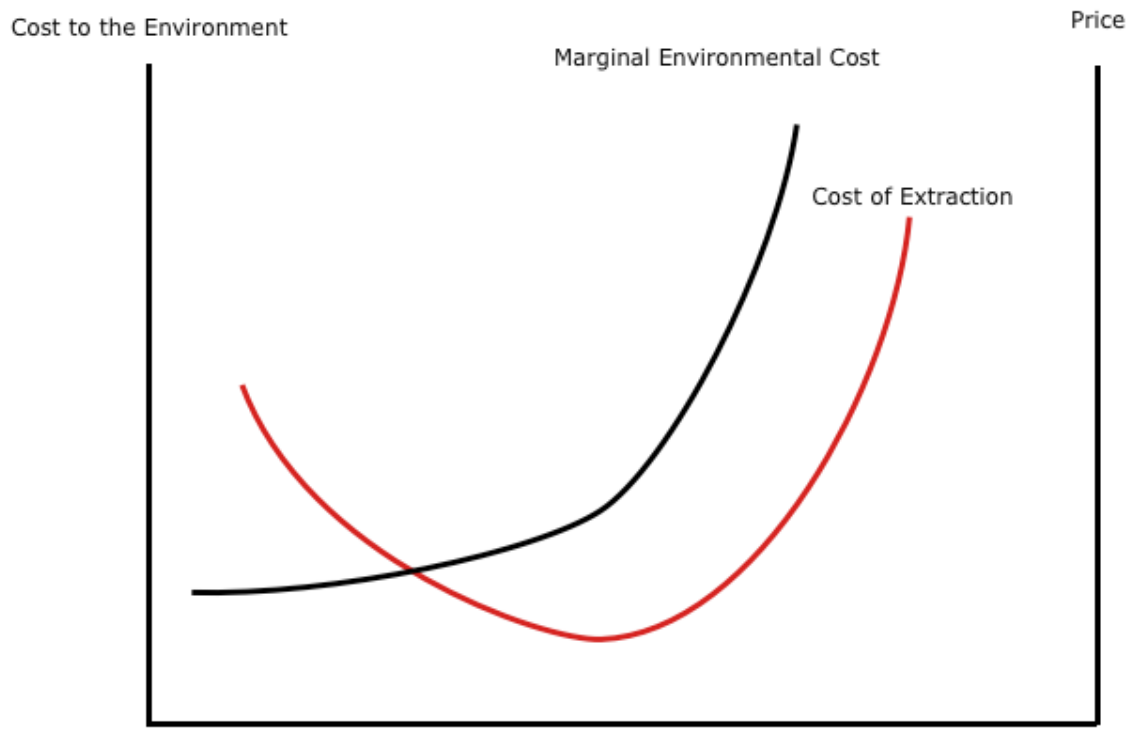

World Resources Extracted

55 Reuters, "Oil Exploration costs rocket as risks rise". http:// www.reuters.com/article/2010/02/11/us-oil-exploration-riskanalysis-idUSTRE61A28X20100211
56 http://www.dangersoffracking.com

57 Kxan Website, "Earthquake Expert Acknowledges Fracking Risks". http://www.kxan.com/news/texas/earthquake-expertacknowledges-fracking-risks 
as oil and gas companies are exempt from the clean water act, the safe drinking water act and the clean air act. Significant damage to human and animal health has been recorded in the land nearby, which is shown to contain high levels of benzene, carbon di-sulphide, arsenic, cadmium, chromium, lead and barium. Water sheds which have been poisoned by plastics, carcinogens, neurotoxins and endocrine disrupting chemicals have also created a public health crisis in many American states. Environmental damage includes land scarring, air pollution, blowouts, accidents, truck traffic and an enormous amount of water required to support fracking operations. In fact, between 1-7 million gallons of water are needed to start drilling any well (which can be drilled in up to 18 locations each). Taking into account that 450,000 wells exist in America today, with many hundreds of thousands of new wells being proposed, a national health crisis could follow, not to mention the extremely wasteful use of water.

Damage to water aquifers occurs when the cement casing cracks, dissolves, shrinks or corrodes, allowing gases to migrate to underground water sources. The fluid used in fracking includes corrosion inhibitors, gel-ants, drilling additives and viscosifiers, many of which are still unknown due to the the fluid's status as proprietary (i.e. fracking fluid is protected from disclosure). The quote underneath, described by the Society of Petroleum Engineers study titled 'Why Oilwells Leak: Cement Behaviour and Long Term Consequences', explains gas migration to natural aquifers.

"The consequences of cement shrinkage are non trivial: in North America, there are literally tens of thousands of abandoned, inactive, or active oil and gas wells, including gas storage wells, that currently leak to the surface. Some of the gas enters shallow aquifers, where traces of sulphurous compounds can render the water non-potable, or where the methane itself can generate unpleasant effects such as gas locking of household wells, or gas entering household systems to come out when taps are turned on". ${ }^{58}$

The degree which well casings fail is of great concern today. A Slumberger oilfield review, titled 'From Mud to Cement - Building gas Wells', demonstrated that $6 \%$ of wells were affected by sustained casing pressu-

58 Maurice B Dusseault, Malcolm N. Gray, Pawel A Nawrocki, "Why Oilwells Leak: Cement Behavior and Long Term Consequences", Society of Petroleum Engineers, SPE 64733. re (SCP) upon immediate use. The consequence of SCP is surface gas leaks.

"The presence of SCP appears to be related to well age; older wells are generally more likely to experience SCP. By the time a well is 15 years old, there is a $50 \%$ probability that it will have measurable SCP in one or more of its casing annuli. However, SCP may be present in wells of any age."

When presented on a global scale, the oil well company Archers documents that $45 \%$ of the 6,650 wells in the Gulf of Mexico have 'integrity issues'. By comparison $34 \%$ of the North Sea wells in the UK (of 1600 ) and $18 \%$ in Norway (of 482 ) also experience the same issues. In such wells, there is a $40 \%$ risk of an 'uncontrolled discharge', which would theoretically cause problems similar to the Gulf of Mexico disaster. $^{59}$

In the majority of cases where wrongful acts are observed and proven, companies receive monetary fines. The real issue is that the changes made to the environment by these companies are permanent and grossly underestimated. Whole ecosystems have been wiped out as rivers become polluted, which kill off all local aquarian, avian and mammal life. In 1987, the Environmental Protection Agency (EPA) concluded in a publication that water contamination was caused by hydraulic fracking, something which is under thorough investigation today. ${ }^{60}$

Fracking is one of the many examples where environmental variables need to be quantified when analysing economic projects. This can also be related to population growth, which raises the need for raw materials and often causes environmental destruction through their extraction. The fact that these practices used today despite these warnings shows the profound need to increase the supply of energy, regardless of the long term cost to the environment.

A specific case where this notion is especially pertinent is the Keystone XL pipeline, which is currently in construction. This is a perfect example of the conflict between economic growth and environmental protection today, and how a lack of economically

59 Ken Feather, "Archer The well company powerpoint presentation", Better Well Integrity, 30 March 2011.

60 EPA Report to Congress, "Management of Wastes from the Explorations, Development and Production of Crude Oil, Natural Gas and Geothermal Energy", 1987, Vol. 1 of 3. 
quantifying the environment is remarkably dangerous. On the positive side, the Keystone XL pipeline would alleviate America's dependency on oil from middle eastern countries and potentially offers 830.000 barrels of oil a day from Alberta to the gulf coast. $^{61}$

The benefits to the American economy are obvious; 40.000 new jobs (according to Transcanada corporation advertisements) which could remediate high unemployment figures, access to a cheap and lasting supply of oil, and the ability to delay the implementation of costly (and potentially unproven) green technologies. All of these benefits represent the essence of short term growth, a rise in GDP and an increase in available jobs for the national workforce; at the cost of the environment. For the sake of impartiality, the issues raised by Friends of the Earth include large scale water waste (tailing ponds), deforestation, destruction of indigenous populations, emissions of toxic gases and the potential for environmental catastrophe. ${ }^{62}$ The National Wildlife Federation also commented that "if expansion of tar sands goes unchecked, it will be impossible to reach our goals to reduce global warming pollution, seriously harming both people and wildlife". ${ }^{63}$

So why are such unpredictable and potentially dangerous projects currently being undertaken? The simple answer is to satisfy growing energy needs and to offset the dependance on a depleting global oil supply, however there is also a serious political undertone that compels governments to approve hydraulic fracking. As the majority of large natural energy sources are currently found in areas with political instability, there is a sense of urgency to find alternatives as these resources become increasingly scarce. The economies and political structures of the most developed countries are predicated upon the continual supply of raw materials from their less developed or developing neighbours, and in the event of an outbreak of war supply could be restricted. Hydraulic fracking therefore provides the avenue to energy independence and therefore political security, albeit at dizzying environmental costs. The

61 Transcanada Website, http://keystone-xl.com/about/theproject/

62 Friends of the Earth Website, http://www.foe.org/projects/ climate-and-energy/tar-sands/keystone-xl-pipeline

63 National Wildlife Federation Website, http://www.nwf.org/ What-We-Do/Energy-and-Climate/Drilling-and-Mining/ Tar-Sands/Keystone-XL-Pipeline.aspx aim of this and next generation therefore is to find a medium whereby energy independence is achieved without the destruction of the environment, though no long term answer has yet been provided. Environmental protection at all costs would stifle economies, production and technological advance, whilst a pro-energy agenda would irrevocably endanger our climate, biodiversity and wellbeing on both a health and social level.

\subsection{Environmental Damage and Overpopula- tion}

How is environmental damage in this capacity linked with overpopulation? Firstly, it is obvious to mention that with increased numbers, our demands for natural resources rise. The desire to extract and use these resources for profit in our current economic paradigm also would justify the environmental damage necessary to utilise these resources. Furthermore, the consumption of these resources are being driven by two factors; the increase in nominal population together with the desire of most developing countries to adopt consumption levels similar to the the western world. As the most easily accessible sources of energy become depleted (North Sea Gas for example), governments and energy companies are considering the extraction of raw materials in areas which were previously overlooked due to their environmental value. Nevertheless, the incessant thirst for these resources and the perpetuation of our lifestyles has created an economy where environmental beauty holds no monetary value and its destruction is a necessary evil to continue our way of life.

Inevitably, the environmental cost increases with each approved project. The Amazon, the lungs of the planet, is disappearing at a rate of $5.843 \mathrm{sq} . \mathrm{km}$ a year, with a 2013 report releasing the findings of a $28 \%$ year on year rise in deforestation. ${ }^{64}$ This would not have been so dire if the demand for wood and the necessity for arable land wasn't so acute. In addition, the current level of carbon dioxide in the atmosphere is now 396.81 parts per million, the highest on record. ${ }^{65}$ This level is more alarming when it is explained that humans have never lived on the planet with such high amounts of carbon dioxide, alongside ever increasing amounts of deforestation.

64 http://www.bbc.co.uk/news/world-latin-america-24950487

$65 \mathrm{CO}_{2}$ now website - http://co2now.org 
Accepting that $\mathrm{CO}_{2}$ emissions are considered harmful to the environment, together with the hypothesis that population growth intensifies demand for projects such as the Keystone XL pipeline to satisfy our demands, it is worth exploring the correlation between the amount of $\mathrm{CO}_{2}$ in the atmosphere and population growth. Assuming these aforementioned connections to be valid and no other excessively large variables having an impact on $\mathrm{CO}_{2}$ levels in the atmosphere, the author hypothesizes a relatively large positive correlation between these two variables. Of course this correlation must be examined on a global scale, rather than a country specific one, and therefore the result is only as reliable as the source data. Correspondingly, the United States Census Bureau was again chosen for midyear world population between 1959 and $2012 .{ }^{66} \mathrm{CO}_{2}$ levels were obtained from the National Oceanic and Atmospheric Administration (NOAA) for the same timeline. The NOAA is one of the few sources for this data, which is extremely hard to procure, and has been made available for general public use. ${ }^{67}$

The yielded correlation between $\mathrm{CO}_{2}$ emissions and population growth was 0.9955 , a staggeringly high correlation. On the basis of the assumptions made in this paper, we can suggest that population growth is the main driver for increases in $\mathrm{CO}_{2}$ emissions, with a high linear relationship. An additional reference which can be used to corroborate this finding is the analytical framework provided by Schleicher and Klöppl, ${ }^{68}$ who consider the following formula to elucidate the demand for emissions:

$$
\begin{aligned}
& \mathrm{C}=\mathrm{CO}_{2} \text { Emissions } \quad \mathrm{Q}=\mathrm{GDP} \\
& \mathrm{P}=\text { Population } \quad \mathrm{E}=\text { Total Energy Supply } \\
& \mathrm{C}=\mathrm{P} *(\mathrm{Q} / \mathrm{P}) *(\mathrm{E} / \mathrm{Q}) *(\mathrm{C} / \mathrm{E})
\end{aligned}
$$

The three categories in brackets were then termed 'economic activity', 'energy intensity' and carbon intensity'. It is instantly noticeable that all three of these are dictated by population once again. Economic activity and energy intensity both contain the component GDP, which as proven earlier is highly correla-

66 United States Department of Commerce, http://www.census. gov/population/international/data/worldpop/table_population.php

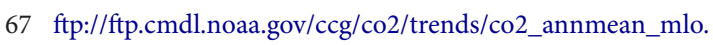
txt

68 Schleicher \& Köppl, "Scanning for Global Greenhouse Gas Emission Reduction Targets and their Distributions 2013". ted with population. In this sense, population acts as the fuel for GDP. The supply of energy is also dictated by the number of people in the sample population, as the energy grid is built to serve the needs and wants of the population and to make a profit through normal means. This formula and its subsets, therefore, support the author's hypothesis and offer insightful avenues concerning how population growth impacts on secondary variables.

Governments and world organisations have set many goals towards the reduction in greenhouse gas emissions, including $\mathrm{CO}_{2}$. The $20-20-20$ is an agreement by the European Union Commission to reduce greenhouse gases to $20 \%$ lower than 1990 levels by 2020, whilst the UK has its own target of reducing emissions by $80 \%$ before 2050 . Unfortunately, previous emissions objectives have not been met, and without American and Chinese participation with similar goals, the overall effect will be greatly diminished. In truth, it is extremely likely that the UK will achieve its 2050 goal, as one of the prerequisites for this is to raise the price of carbon to such an extent (up to 250 euros a tonne) that renewable energy sources are favourable.

Karl Aiginger added in May 2013 in a publications that "progress (in energy reduction and resource use) so far is however significantly at odds with the shift in the technology and growth path needed. Nowhere has borne witness to an absolute decoupling of energy or resource growth from output growth over a longer period and specifically not for growth rates compatible with low unemployment." ${ }^{169} \mathrm{He}$ also notes that an increased water shortage has hindered the expansion of hydro electric energy systems.

Moreover, although all nations agree that climate change is detrimental, there is a lack of consensus on the negative externalities and their social, economic and environmental costs. These disputes all point to the need for a Tobins Q style assessment, where the cost of replacing environmental damage is equated into cost projections. This idea is tied with the concept of sustainability, and to their credit western European countries have taken important steps to implement this. Nevertheless, the true environmental damage is occurring in developing countries, such as China, India and Brazil.

\footnotetext{
69 Karl Aiginger, "The 'greening' of industrial policy, head-
} winds and a possible symbiosis". 


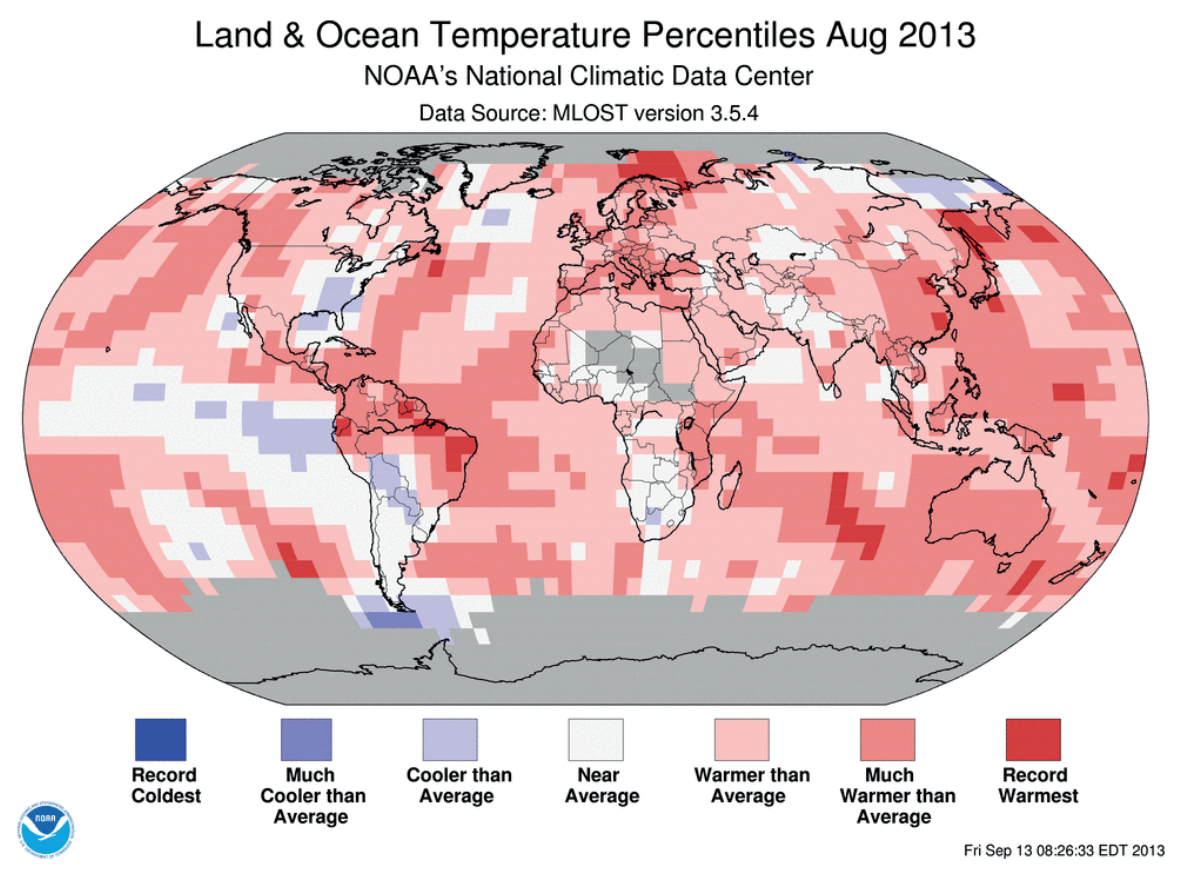

The effects of such damage is much more global, as displayed in the August 2013 global sea surface temperature anomalies posted by the NOAA. Figure 23 demonstrates a record number of high temperature abnormalities, a clear indicator of the onset of climate changes. ${ }^{71}$

The most serious questions that can be posed are very simple: how can we justify the (sometimes permanent) damage to the environment by undertaking current economic projects? Secondly, is there any way whereby the environment can be quantified, such that governments, corporations and individuals see its improvement as an economic benefit? Socially and morally it is perfectly clear that the better the ecosystem is, the better our health becomes. Air quality, water standards, availability of land, growth of forests and the health of the oceans are very expense projects and currently provide little economic benefit. The long term benefits of an improved biodiversity provide deeper insights into biology and chemistry which would lead to increased human longevity and health. Unfortunately, preserving an area of natural beauty does not allow for the extraction of resources

71 NOAA Global Sea Surface Temperatures, http://climateimc. org/en/original-news/2013/09/21/global-sea-surface-temperatures-record-level-august-2013-says-noaa or the expansion of corporate/industrial operations, which therefore hampers economic growth.

The first question posed in the paragraph above can be easily answered by our addiction to natural resource consumption. The main individual aim today is the perpetuation or improvement of our lifestyles, which require resources to produce energy, food and luxury goods. Our society is therefore driven by these needs, and any derivation from a pattern of increased consumption is seen as a step backwards in our social development. As a result, humans adopt a 'out of sight, out of mind' approach whereby we are conscious of the environmental damage but are able to justify it as a 'necessary evil' in today's world. Secondly, environmental destruction reflects a cumulative effect on ecosystems, a proportion of which have yet to bear fruit. For example, when climate change starts to directly effect business operations to such a degree that it can be economically quantifiable, it will be too late to reverse the effects. Consequently, it is essential to forecast future environmental costs and quantify them today, a procedure which is entirely foreign to polluting corporations.

The answer to the second question posed is far more complex. In most cases, the best method would be to offer a monetary incentive to encourage environ- 
mental protection and monetary fines to discourage destruction. The current problem is that operations such as forestry, mineral extraction, fishing, industrial agriculture and non renewable energy consumption have now become so large and lucrative that only extreme amounts of money would discourage such environmentally damaging operations. Similarly, the fines are nowhere near as harsh as they should be. For instance, in 2012 Shell has been fined $\$ 1.5$ billion by the Nigerian government for environmental degradation in a legal case which started over a decade ago. ${ }^{72}$ When the case began, Shell simply refused to pay the fine, showing the power that oil companies have. Since the majority of raw materials are extracted in developing countries, the strength of their governments to enforce such environmental regulations comes under scrutiny. Ideally, such reckless regard for environmental law should see Shell banned from such operations, however a monetary fine will settle even permanent eco-destruction in today's legal and economic rulebook. So why did Shell allegedly cause such destruction, which included gas flaring, 1.5 million tonnes of oil spills, destruction of wetlands, summary execution of humans and crimes against humanity ${ }^{73}$ Because the environment was not quantifiable and economic gains provided the incentive to rationalise such actions, even to this degree.

The summary of this chapter is clear; an increasing population requires improvements in quantifying today's environmental assets. The method may still be unknown, however the dire need for reforms in the energy industry to reduce consumption of fossil fuels necessitates such action. Sustainability is the real key issue, as mentioned in the Marine Ecology Progress Series:

"The excess of the worlds resources or 'overshoot' is possible because resources can be harvested faster than they can be replaced. The cumulative overshoot from the mid 1980's to 2002 resulted in an ecological debt that would require 2.5 planet earths to pay. In a business as usual scenario, our demands on planet Earth could mount to the productivity of 27 planets by $2050 . " 74$

72 Rory Carroll, "The guardian - Shell told to pay Nigerians $\$ 1.5$ bn pollution damages". http://www.theguardian.com/ world/2006/feb/25/oil.business

73 Centre for Constitutional Rights, Factsheet: Shell's Environmental Devestation in Nigeria. https://ccrjustice.org/learnmore/faqs/shell\%2526\%2523039\%3Bs-environmentaldevastation-nigeria

\section{Evaluation of Results and Conclusion}

The results of this paper leave little doubt of the necessity of increased awareness when considering population growth. Indeed, many economic and environmental difficulties today are derived from the continuous expansion of our numbers without the proper understanding of maintaining a suitable and sustainable environment to draw resources from. The role of scarcity is a fundamental rule to our economy, however the degree of scarcity is controlled by population size. As a result, growth under increased scarcity can be a dangerous cocktail.

It goes without saying that there are huge barriers, both morally and legally, to curb our population size. In the United States, it is considered patriotic for citizens to fight for the preservation of their way of life, which is tied to the fulfilment of its appetites through foreign resources. Demographic changes through increases in population are encouraged by all forms of organised religion today as a means of spreading the faith. From an ethical perspective, it is considered a human right to have and raise as many children as one desires. These are all perfectly legitimate opinions, despite the changing world environment and the restrictions it may enforce. Yet the growth rate of our species is quite astounding. For example, during one of Bangladesh's recent floods, 139,000 people lost their lives, which is a real tragedy under any circumstance. The time taken in Bangladesh to increase it's population by 139,000 people was just 2 and a half weeks - so even mass scale disasters do not deter our relentless increase in numbers. ${ }^{75}$ As a result, if human numbers are to stabilise, it will have to come from a change in our customs and reproductive decisions.

As concluded in chapter 1 of this publication, there are valid reasons to doubt the prediction of the United Nations forecast of a population slowdown. The author therefore presents the following conclusion: assuming the perpetuation of current population growth rates, the United Nations forecast is a significant underestimate. Nevertheless, there are 2 significant and contrasting forces which act to determine future populations, namely environment restrictions (which could dampen growth) and the level of social and religious change in less affluent countries (the less theocratic and the more socially aware societies become, e.g. through

75 Alexandra Paul, Overpopulation Facts Presentation, TedX- 
the education offemales, the greater the deceleration of population growth).

The implication of increasing proportions of the budget being allocated to social security, income security and medicare is the urgent need for reform in these areas. Indeed, as these costs continue to rise, alternative expenditures such as education will be overlooked or cut, alongside defence spending, science and research projects and veterans benefits.

Relating to the statistical analysis in this paper, we see that population growth is heavily correlated with major economic parameters, such as the monetary base, GDP growth, debt levels and the rise in current account deficits (in the United States, though the author would also extend this hypothesis to large developed countries). These correlations are also surprisingly high when considering the boom/bust cycles within this 50 year period of data analysis. There is also strong evidence for a positive relationship between population growth and $\mathrm{CO}_{2}$ emissions. Whilst these correlations are not unexpected, (indeed many are somewhat intuitive) the degree of the correlations demonstrates that population levels need to be taken far more seriously in economic and political discourse. It is the 'elephant in the room' when discussing pension crises, raw material prices, environmental management and wealth inequality. It is also the main inhibitor of climate policy objectives. Unfortunately, until now it is the author's strong belief that this is a neglected topic at a critical moment in our financial development.

The question arises why this time in our history is so much different than in the past. There are previous cases where ageing populations were substituted by the "baby boom' generation, so why can't this happen once again? The answer is somewhat sobering, "because this time the circumstances are very different". We have neither the space, nor the resources, to accommodate another baby boom generation, which would again kick the current economic problems over to the next generation. Through modern technology we are able to prolong human life, and there is no reason to suggest that longevity patterns will suddenly stagnate as technology continues to develop.

Technology itself will play a large role in the coming decades. Tony Judt explains brilliantly the onset of mechanisation, whereby machines will replace hu- mans to do arbitrary work more efficiently. ${ }^{76}$ Whilst increasing productivity, this will also increase the strain on unemployment levels and pose the obvious question "do we have enough jobs for all these people in the world?" As the most basic and monotonous jobs replace the more unskilled members of the workforce, what effect will this have on the long term unemployed, and more importantly the distribution of wealth in developed countries? A calculated prediction would be that wealth will become more unequal and the unemployment rate will rise, unless the need for a large number of long term and labour intensive jobs arises. So far, there is little evidence to suggest that job creation will reach the necessary levels to accommodate both the current and future work force.

In essence, although not directly observable, it is safe to surmise that the marginal utility of labour is diminishing in our economic environment i.e that if the population increased by $5 \%$, it would have less of a positive influence on the economy than the previous $5 \%$. This is due to the existing large number of unemployed people. It can be concluded that the benefits of population growth on the market are decreasing over time. The ramification of such unemployment (in this case the continuous rise in nominal unemployment is referred to) results in the manifestation of a welfare state, where it is increasingly difficult to obtain a job due to high demand, inflation persists (expanding the wealth gap) and the overall standard of living sequentially drops. Together with the prognosis that the increased scarcity of food, water and energy, higher percentages of real personal disposable income will be required to cover the basic costs of living. In addition, there is a deflationary pressure on wages, as people are willing to accept lower wages for the security of employment. As a consequence, we can anticipate in this economic paradigm with continual population growth a lower standard of living than in the previous generation. Admittedly, technological advances could serve to negate this effect and raise the standard of living, though real wealth is eluded. It is possible to analyse this effect by looking at historical trends between average wages and inflation, though technological innovation, implementation and effect are difficult to observe and quantify.

William Fielding Ogburn, an American statistician and sociologist, was a strong advocate in 'Tech-

76 Tony Judt, "Ill Fares the Land", 2010. 
nological Determinism'77, which principally states that "technological progress is the primary engine of progress, but tempered by social responses to it." Although this may have been more apposite more than a century ago, the continual refinement of technology today is the primary engine of profit_(rather than progress), but is tempered by the social adaptability of demand. For instance, it would far more beneficial to devote considerable efforts and investments into safe and renewable energy sources, including unconventional ones such as geothermal, however there is little profit in large investments to produce free energy. The lack of public awareness regarding the abundance of such energy also shows a lack of social adaptability, therefore the reliance on oil, coal and shale gas will persist.

As mentioned at the beginning of this paper, David Attenborough mentions in his documentary film that populations require water, land and energy to survive. Having already considered energy, we can also look at land and water as finite resources. Derived from this are food, water and housing prices. Consequently, unless significant strides are taken regarding laboratory grown meat, hydroponics (which are currently being researched) and desalination, prices of necessity goods will rise, and since these are becoming scarce resources, they will logically rise at an even faster rate than populations. For example, the size of Lake Chad has decreased by $95 \%$ between 1960 and 2000, the majority of which is caused by population growth. ${ }^{78}$ Water is rapidly becoming a scarce resource and prices will adjust correspondingly. The reaction to the prognosis of future shortages has been a "land and resource grab' approach by both countries and private individuals. China has reportedly bought up to 3 million hectares of farmland in the Ukraine to support its population, ${ }^{79}$ whilst Saudi Arabia, Qatar, Kuwait and Abu Dhabi are showing interest in Sudan, Kenya, Nigeria, Tanzania, Malawi, Ethiopia, Congo, Zambia, Uganda, Madagascar,

77 William Fielding Ogburn, "Social Change with Respect to Culture \& Original Nature, 1922".

78 Frank Jacobs, "95 The incredible Shrinking of Lake (Chad, That is). http://bigthink.com/strange-maps/95-the-incredible-shrinking-lake-chad-that-is

79 Channel 4 News, "China buys huge swathe of Ukraine in grab for farmland". http://www.channel4.com/news/chinaukraine-farmland-food-security-investment-overseas
Zimbabwe, Mali, Sierra Leone and Ghana. ${ }^{80}$ T. Boone Pickens, one of the worlds richest individuals, has successfully cemented himself as the largest water owner in the United States after he was able to secure the rights to the Ogallala Aquifer, which is the largest in North America and spans 8 states. ${ }^{81}$ This shows that not only land, but resource consolidation, is one of the primary aims of individuals and countries in the $21^{\text {st }}$ century. Even former President George W. Bush purchased land in Paraguay next to the Guarani Aquifer. ${ }^{82}$ Water Stress in itself is in a dire situation, as portrayed by the World Resources Institute in 2013. Figure 24 clarifies that many countries today fall under the categories of either high stress $(40 \%-80 \%)$ or extremely high stress $(80 \%+) .{ }^{83}$ The previous few paragraphs have described the essence of a relationship between production, wages and purchasing power, which is displayed in figure 25. The role of population is an independent one which applies downward pressure on wages and pushes inflation upwards.

The conclusion to this paper leaves open a great number of opportunities and future research fields. The aim of this paper is to raise awareness of population and how it should be considered an important variable when analysing current economic paradigms and forecasting future ones. It highlights the pressing need for changes in our conception of growth as a product of demand, and discusses the harm which current population growth will cause. Population decline may be detrimental to economic growth in the short run, though it is far preferable to a world with 10 billion people and a great shortage of life's basic necessities.

Additionally, we are observing several areas of environmental degradation which will result in quantifiable losses to the economy in the future through

80 The Guardian Newspaper, "How food and water are driving a $21^{\text {st }}$ century land grab". http://www.theguardian.com/environment/2010/mar/07/food-water-africa-land-grab

81 T. Boone Pickens, "A Water Baron for the $21^{\text {st }}$ Century", CBS News .http://www.cbsnews.com/news/t-boone-pickens-awater-baron-for-the-21st-century/

82 Columbia Water Centre, "The Guarani Aquifer: a little known water resource in South America gets a voice". http://blogs.ei.columbia.edu/2010/04/13/the-guarani-aquifer-a-little-known-water-resource-in-south-america-gets-avoice/

83 World Resource Institute, "Water Stress by Country 2013".

84 Source: http://www.wri.org/resources/charts-graphs/waterstress-country 
Fig. 24: Water Stress by Country - World Resource Institute ${ }^{84}$

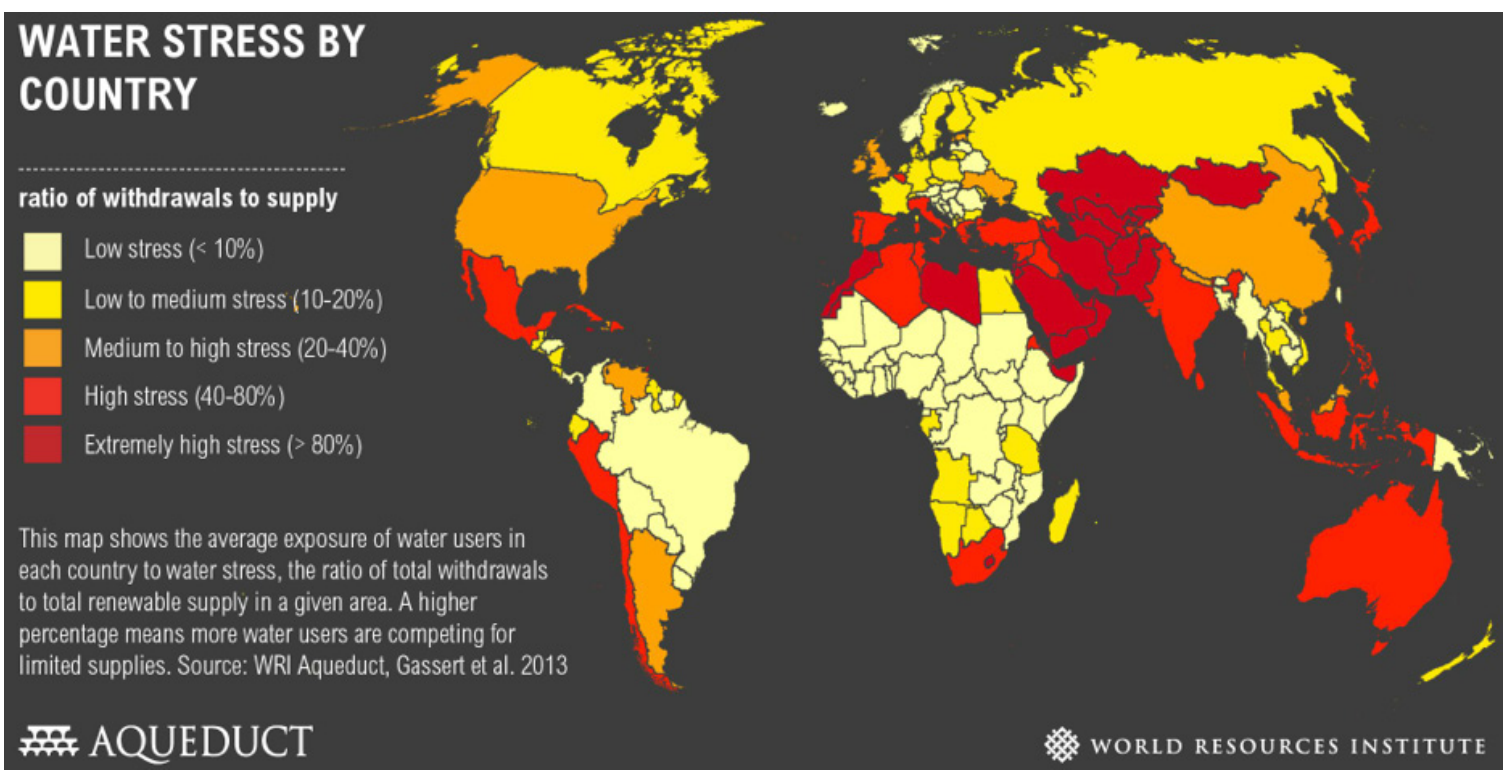

the overuse of resources today. In essence we are sequestering the wealth of future generations by over-consuming today.

The use of these resources geographically has not been delved into as much as the author would have wished, but it is worth mentioning that the average United States citizen uses 32 times the number of resources as an individual in an African country ${ }^{85}$. Consequently, the burden of sustainability must be recognised by the developed world.

Fig. 25: Development of Production, Wages and Purchasing Power over Time

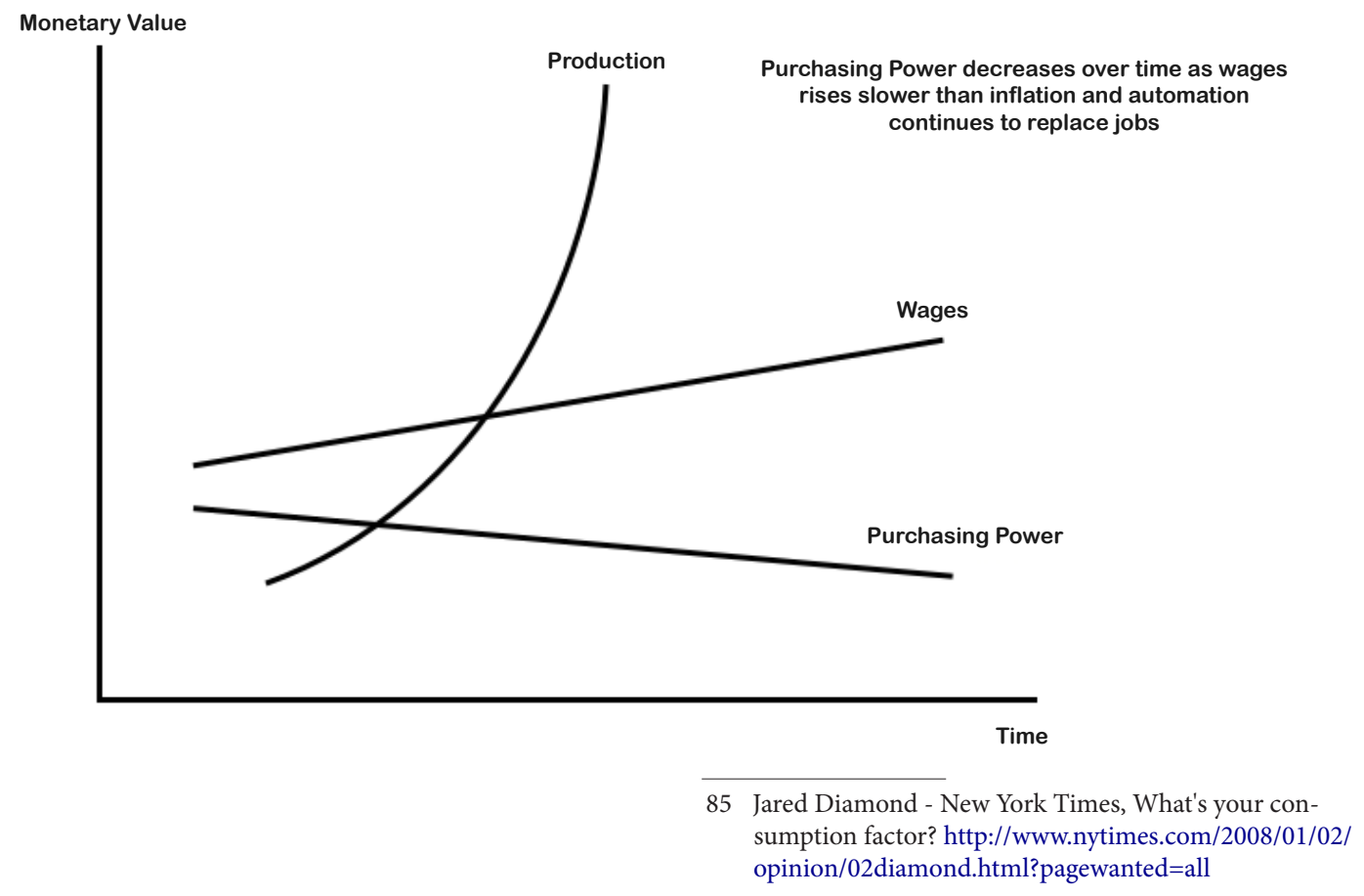


As an addendum to this paper, the author wishes to emphasise that in his opinion the one child policy does not work. Forcing the reproductive choices of individuals is ethically just as deplorable as denying women education, which both enforce subservience of their reproductive decisions to their husbands. Instead, education in both the developing and developed world is required, such that people are aware of their choice to propagate on a macro scale. At the end of the day, we cannot keep growing ad infinitum. ${ }^{86}$ The final quote below originated from the United $\mathrm{Na}$ tions world monitoring report in 2001. Although it demonstrates that we are well aware of the environmental impact we create, which is a step in the right direction, the information in the paper suggests our attempts to find a balance between economic growth and a sustainable environment have been unsuccessful. Perhaps if population growth and its influence of raw material demand were taken in account, policy to minimise or reverse some of the degradation could be more effective.

"Many of the environmental issues of greatest concern today involve resources that are to a greater or lesser degree "common property resources". Economic theory predicts, and much experimental evidence demonstrates, that unhindered access to such resources eds to overuse, misuse, and quality degradation. in the absence of effective social mechanisms to limit and ameliorate the tendency for common property resources to be overused and degraded, population growth will tend to exacerbate such problems." ${ }^{\text {"87 }}$

\section{Source Material}

\section{Press Releases}

Allianz knowledge, http://knowledge.allianz.com/?363/how-female-empowerment-affects-population-growth

Anderson Richard, "UK debt and deficit: All you need to know", BBC News. http://www. bbc.co.uk/news/business-25944653

86 The Express Newspaper, "Sir David Attenorough warns of impact loss of green space is having on children". http:// www.express.co.uk/news/nature/449015/Sir-David-Attenborough-warns-of-impact-loss-of-green-space-is-having-onchildren
Barro Josh, "Here's What That Really Means". Business Insider, 95\% of Income Gains Since 2009 Went To The Top 1\%, http://www.businessinsider.com/95-of-income-gains-since-2009-went-tothe-top-1-heres-what-that-really-means-2013-9

BBC News Website: South Asia, Latin America and Science and Nature

BBC South Asia News: www.bbc.co.uk/ news/world-south-asia

Bigthink Website: The incredible Shrinking of Lake Chad

Black Richard, "Only 650 years left for Sea Fish", BBC Science/Nature. http:// news.bbc.co.uk/1/hi/6108414.stm

Bloomberg Website: www.bloomberg.com/news/

Business Insider: www.businessinsider.com

Carroll Roy, "The guardian - Shell told to pay Nigerians $\$ 1.5$ bn pollution damages". http://www.theguardian.com/ world/2006/feb/25/oil.business

CBS News: www.cbsnews.com/news

Channel 4 News: www.channel4.com/news/ CNN Money: money.cnn.com

Centre for Constitutional Rights: ccrjustice.org

CNN Money, Obama admits 95\% of income gains gone to top $1 \%$, http:// money.cnn.com/2013/09/15/news/ economy/income-inequality-obama/

$\mathrm{CO}_{2}$ now website: http://co2now.org

Columbia Water Centre

Douglas Jason and Ilona Billington, "UK Balance of Payments Worsens", Wall Street Journal. http://online.wsj.com/news/articles/SB10014 24052702304866904579269712811947376

Federal Reserve Monetary Base, http://research.stlouisfed.org/fred2/data/BASE.txt

Federal Reserve M2, http://research.stlouisfed.org/fred2/data/M2.txt

Friends of the Earth Website: http://www.foe.org

$\mathrm{ftp} / / / \mathrm{ftp} . \mathrm{cmdl}$.noaa.gov/ccg/co2/trends/ co2_annmean_mlo.txt 
http://www.bbc.co.uk/news/worldlatin-america-24950487

India Online Website, Indian Population: http:// www.indiaonlinepages.com/population

Jacobs Frank, "95 The incredible Shrinking of Lake (Chad, That is). http://bigthink.com/strange-maps/95-the-incredible-shrinking-lake-chad-that-is

Kxan Website: www.kxan.com

Lahart, Justin "Companies Cling to Cash". Wall Street Journal, 10/12/2010. http:// www.businessinsider.com/95-of-incomegains-since-2009-went-to-the-top-1-heres-what-that-really-means-2013-9

Lyons, Chantel, "The injustice of Overpopulation", The Huffington Post. http:huffingtonpost. co.uk/chantal-lyons/overpopulation-injustice_b_2641385.html

Macro Investing Strategy Website: www. macro-investing-strategy.com/

Marine Ecology Progress Series: www.int-res. com/journals/meps/meps-home Metro Newspaper: http://metro.co.uk

National Geographic http://ngm.nationalgeographic.com

National Wildlife Federation Website: http://www.nwf.org/

New Geography Website: http:// www.newgeography.com/

OECD, GDP Data. http://stats.oecd.org/Index.aspx? datasetcode=SNA_TABLE1\#

Pickens T. Boone, "A Water Baron for the $21^{\text {st }}$ Century", CBS News .http://www. cbsnews.com/news/t-boone-pickens-awater-baron-for-the-21st-century

Reuters: "Oil Exploration costs rocket as risks rise". http://www.reuters.com/article/2010/02/11/us-oil-exploration-riskanalysis-idUSTRE61A28X20100211

Saez, Emmanuel "Striking it Richer: The Evolution of Top Incomes in the United States". UC Berkeley, September 3, 2013. http://eml.berkeley.edu/ saez/saez-UStopincomes-2012.pdf
Senator Bernie Sanders: www.sanders.senate.gov

Statistisches Bundesamt Deuschland, Population Data. https://www.destatis.de/DE/ Startseite.html?nsc=true\&https $=1$

St. Louis Federal Exchange: http://research. stlouisfed.org/fred2/data/BASE.txt

The Economist: www.economist.com

The Guardian Newspaper: http://www. theguardian.com/environment/

The Huffington Post: Chantal Lyons, Overpopulation Publications: www.huffingtonpost.co.uk/chantal-lyons

The Washington Post: www.washingtonpost.com

The Wall Street Journal: http://online.wsj.com

Transcanada Website. Press Releases and the About the Project Section: http:// keystone-xl.com/about/the-project/

UPI News: www.upi.com/Top_News/US

United Nations Press Release: http://esa.un.org

United States Environmental Protection Agency: http://www.epa.gov

Weisman Alan, "Live interview on Realtime with Bill Maher", 14/03/2014.

With House Office of Budget and Management Fiscal year 2014 Historical Tables, pg. 27-70. http://www.gpo.gov/fdsys/pkg/BUDGET2014-TAB/pdf/BUDGET-2014-TAB.pdf

\section{Books and Publications}

Aiginger Karl, "The 'greening' of industrial policy, headwinds and a possible symbiosis, 2013, page 5. http://www.foreurope. eu/fileadmin/documents/pdf/PolicyPapers/WWWforEurope_Policy_Paper_003. pdf (Accessed September 30, 2014)

Dorling, Danny, "Population 10 billion", 2013. London: Constable \& Robinson.

Dusseault Maurice B, Gray Malcolm N., Nawrocki Pawel A, "Why Oilwells Leak: Cement Behavior and Long Term Consequences", Society of Petroleum Engineers, SPE 64733. https://www. onepetro.org/conference-paper/SPE-64733-MS 
EPA Report to Congress, "Management of Wastes from the Explorations, Development and Production of Crude Oil, Natural Gas and Geothermal Energy", 1987, Vol. 1 of 3.

Feather Ken, "Archer The well company powerpoint presentation", Better Well Integrity, 30 March 2011.

Hauge Kjellrun Hiis, Cleeland Belinda and Wilson Douglas Clyde, "Fisheries Depletion and Collapse", IRGC Report: http://irgc.org/wp-content/ uploads/2012/04/Fisheries_Depletion_full_case_ study_web.pdf (Accessed September 30, 2014)

Judt Tony, "Ill Fares the Land". New York: Penguin Press, 2010.

Komáromi András, "The effect of the monetary base on money supply - Does the quantity of central bank money carry any information?" NMB Bulletin, 2007, pp. 31-37.

Luxembourg Income Study, Inequality - it Matters. http://lisdatacenter.org/wp-content/ uploads/janet-bio/gornick-folio-2013. pdf (Accessed September 20, 2014)

Malthus Thomas, An Essay on the Principle of Population. London: J. Johnson, 1798.

Modern Money Mechanics, A Workbook on Bank Reserves and Deposit Expansion. http://www. rayservers.com/images/ModernMoneyMechanics.pdf (Accessed September 30, 2014)

NOAA National Climatic Data Center, State of the Climate: Global Analysis for August 2013, published online September 2013, retrieved on September 29, 2014 from http:// www.ncdc.noaa.gov/sotc/global/2013/08/

North, Christopher, "Financial Crisis Forecasting: Causes, Effects and Systemic Factors Influencing Financial Crises", page 140. http://othes. univie.ac.at/27974/1/2013-04-30_0610700.pdf

Ogburn William Fielding, "Social Change with Respect to Culture \& Original Nature". New York: B.W. Huebsch Inc., 1922.

Rosenberg Matt, Population Density: http://geography.about.com/od/ populationgeography/a/popdensity.htm
Schleicher Stefan P. and Köppl Angela, Scanning for Global Greenhouse Gas Emission Reduction Targets and their Distributions, 2012, FEEM Working Paper No. 36.

The Hofstede Center, Cultural Tools, Country Comparision. http://geert-hofstede.com/ countries.hmtl (Accessed Septemer 30, 2014)

Terazono Emiko, "Climate extremes inflate food prices", Financial Times Online. http://www. ft.com/intl/cms/s/2/5c4500fc-a518-11e38988-00144feab7de.html\#axzz2zMBDB7JI

UNICEF Website: State of the Worlds Children 2013, Full Report: http://www.unicef.org/sowc2013/ report.html (Accessed September 30, 2014)

United Nations, 1999, Human Development Reports. http://hdr.undp.org/en/reports/global/1999/en (Accessed September 30, 2014)

United Nations Food and \& Agriculture Organisation:, Global Forest Resource Assessment 2010. http://www.fao.org/docrep/013/i1757e/ i1757e.pdf (Accessed Septemer 30, 2014)

United Nations Population Fund, "2013 State of the World Report", http://www.unfpa.org/webdav/ site/global/shared/swp2013/EN-SWOP2013final.pdf (Accessed September 30, 2014)

United States Department of Commerce, Midyear Population of the World 1950-2000. http://www.census.gov/fao.org/docrep/013/ i1757e.pdf (Accessed September 30, 2014)

US Central Intelligence Agency (CIA), The World Factbook 2013. https://www.cia. gov/library/publications/the-world-factbook/ (Accessed September 30, 2014)

World Resource Institute, Water Stress by Country 2013: Paul Reig, Andrew Maddocks and Francis Gassert. http://www.wri.org/ blog/2013/12/world's-36-most-water-stressedcountries (Accessed September 30, 2014)

\section{Documentaries}

Attenborough David, Documentary: How Many People Can Live on Planet Earth

End of the Line Documentary: http://endoftheline.com 
http://www.dangersoffracking.com

Paul Alexandra, TedXTopanga - Overpopulation Facts Presentation: http://www. youtube.com/watch? $\mathrm{v}=\mathrm{fNxctzyNxC0}$

Youtube Link, "Population Matters Online". https://www.youtube.com/watch?v=2H0p OlrXSyI\&list=PL811CD932F936221B 